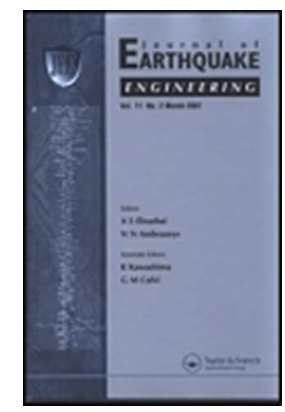

\title{
Masonry Italian code-conforming buildings. Part 2: nonlinear modelling and time-history analysis
}

\begin{tabular}{|r|l|}
\hline Journal: & Journal of Earthquake Engineering \\
\hline Manuscript ID & UEQE-2018-3265.R1 \\
\hline Manuscript Type: & Full Length Papers \\
\hline Date Submitted by the Author: & n/a \\
\hline Complete List of Authors: & $\begin{array}{l}\text { Cattari, Serena; University of Genova, DICCA } \\
\text { Camilletti, Daniela; University of Genoa, DICCA } \\
\text { Lagomarsino, Sergio; University of Genoa, DICCA } \\
\text { Bracchi, Stefano; University of Pavia } \\
\text { Rota, Maria; EUCENTRE, Masonry Structures Section } \\
\text { Penna, Andrea; University of Pavia }\end{array}$ \\
\hline Keywords: & $\begin{array}{l}\text { URM buildings, nonlinear dynamic analysis, seismic assessment, multiple } \\
\text { stripe analysis, equivalent frame modelling }\end{array}$ \\
\hline
\end{tabular}




\title{
Masonry Italian code-conforming buildings. Part 2: nonlinear modelling and time-history analysis
}

\author{
Serena Cattari ${ }^{\mathrm{a}}$, Daniela Camilletti ${ }^{\mathrm{a}}$, Sergio Lagomarsino ${ }^{\mathrm{a},{ }^{*}}$, Stefano Bracchi ${ }^{\mathrm{b}}$, Maria Rota $^{\mathrm{c}}$, Andrea \\ Penna ${ }^{\mathrm{b}, \mathrm{c}}$ \\ ${ }^{a}$ Department of Civil, Chemical and Environmental Engineering, University of Genoa, Genoa, Italy \\ ${ }^{b}$ Department of Civil Engineering and Architecture, University of Pavia, Pavia, Italy \\ ${ }^{c}$ EUCENTRE Foundation, Pavia, Italy \\ *corresponding author: sergio.lagomarsino@unige.it
}

\begin{abstract}
The URM buildings designed to be conforming with the Italian building code, as illustrated in the companion paper by Manzini et al. (2018), were analyzed by performing time-history analyses on models realized using an equivalent frame approach and by adopting two different constitutive laws. Both the effect of record-to-record variability and of epistemic and aleatory uncertainties in modelling were explored. The achieved results constitute the basis for the evaluation of the risk level implicit in Italian code-conforming buildings (Iervolino et al. 2018). Two main performance conditions are considered, namely usability-preventing damage and global collapse limit states.
\end{abstract}

Keywords. Unreinforced masonry, new buildings, nonlinear dynamic analysis, seismic assessment, multiple stripe analysis 


\section{Masonry Italian code-conforming buildings: Part 2: nonlinear modelling and time-history analysis}

\section{Foreword and Assessment Methodology}

This paper illustrates part of the work carried out within the RINTC project (Iervolino et al. 2018) which is addressed to assess the implicit seismic risk of different structural typologies (reinforced concrete, masonry, steel, pre-cast reinforced concrete and seismically isolated buildings) designed according to the Italian building code $(\mathrm{NTC} 08,2008)$. The final aim of the project is then to verify whether these different typologies guarantee a uniform risk across the national territory. Within this framework, this paper specifically discusses the procedure and the results of the seismic assessment carried out on the unreinforced masonry (URM) configurations, designed according to the requirements of the Italian building code (NTC08, 2008) and illustrated in the companion paper by Manzini et al. (2018).

Several regular and irregular configurations with two or three stories were verified with the different design methods allowed by the code (namely "C", "I", "E" configurations), for a set of sites with different levels of seismic hazard, that were identified within the RINTC project. As illustrated in detail in Manzini et al. (2018), "E" buildings represent examples of real modern unreinforced masonry buildings, "C" configurations were conceived as structural variations of regular wall arrangements based on the same architectural plan and "I" buildings incorporate the degrees of irregularity allowed by the code. The aim of the design/verification procedure described in Manzini et al. (2018) was to identify meaningful building-site combinations, complying with code requirements without being excessively over-designed, i.e. with a safety factor as close as possible to unity. These meaningful configurations are the object of the seismic assessment presented in this work, which is carried out using an equivalent frame approach incorporating specific constitutive laws, either mechanics-based or phenomenological, allowing to reliably reproduce the in-plane cyclic response of masonry structural members. Model parameters and dispersion of mechanical properties were estimated starting from experimental results on modern masonry structural elements and components available in the literature. The complete overview of the results of building-site combinations presented in Manzini et al. (2018) is illustrated in the RINTC Workgroup report (2018), whereas, for the sake of brevity, in this paper the attention is focused on the sites characterized by the highest seismicity (L'Aquila and Naples). 
The assessment was carried out by performing nonlinear dynamic analyses (NLDA), which represent the most accurate method currently available for the evaluation of the seismic response of masonry buildings, despite being rarely used in engineering practice. Two main performance conditions were considered, UsabilityPreventing Damage (UPD) and Global Collapse (GC) limit states.

Analyses were carried out following a Multiple Stripe Analysis (MSA) framework (Jalayer and Cornell, 2002, Jalayer, 2003), which consists in computing the distribution of one (or more) engineering demand parameters (EDPs), for different levels of the seismic action experienced by the structure under consideration. To this aim, ten values of the return period of the seismic action were identified and, for each of them, 20 two-components real accelerograms were selected using the conditional spectrum method (Lin et al., 2013) and taking into account the magnitude and distance values of the causative earthquake (Iervolino et al. 2018). For each site and for each soil condition, all the records of each stripe were scaled to provide the value of spectral acceleration resulting from the probabilistic seismic hazard study for the corresponding return period of the seismic action, at a fixed structural period. This period was set equal to $0.15 \mathrm{~s}$, which is compatible with the range of variation of the fundamental periods of the examined URM buildings as carried out from the modal analysis and that varies from a minimum value of $0.083 \mathrm{~s}$ (in the case of two-story buildings) to a maximum value of $0.235 \mathrm{~s}$ (in the case of three-story buildings).

A first set of NLDA was carried out by considering only the effect of the uncertainty related to the seismic action (i.e. record-to-record variability). In the second set of analyses, structural modelling uncertainty was considered as well, by introducing a set of random variables describing the aleatory variability of material parameters and their correlation structure (Franchin et al. 2018), whereas the epistemic uncertainty related to modelling choices was taken into account by proposing a weight to combine the results obtained with the different options (logic tree approach). The results of the two sets of analyses were then compared, to evaluate the effect of the structural modelling uncertainty on the assessment.

\section{Cyclic Nonlinear Modeling of Masonry Elements}

Structural models were developed according to the equivalent frame approach, with the same geometry of the structural elements used in the design phase (Manzini et al. 2018) but adopting strength criteria and constitutive laws able to capture, as much as possible, the cyclic force-displacement behavior of masonry piers and spandrels subjected to lateral loads. Two different nonlinear constitutive laws were used to model masonry 
panels: a piecewise-linear beam model (Cattari and Lagomarsino 2013, Lagomarsino and Cattari 2015) and a macroelement mechanical model (Penna et al. 2014a, Bracchi et al. 2018). Both are implemented in the TREMURI program (Lagomarsino et al. 2013) that was used for performing NLDA.

\subsection{Piecewise-linear model}

The nonlinear beam piecewise-linear model with lumped inelasticity idealization and a piecewise-linear behavior formulated by Cattari and Lagomarsino (2013) will be indicated in the following as NLBEAM-model. The constitutive law allows the description of the nonlinear response until very severe damage levels (DL, from 1 to 5), through progressive strength degradation in correspondence of assigned values of drift (Figure 1a). The hysteretic response (Figure la) is formulated through a phenomenological approach, to capture the differences among the various possible failure modes (flexural type, shear type or even hybrid) and the different response of piers and spandrels.

The model requires the definition of a first set of parameters aimed to describe the initial stiffness of the panel and its progressive degradation, the maximum strength of the panel $\left(V_{y}\right)$ and the progressing of nonlinear response for increasing damage levels ( $\theta_{E i}$ - drift value at the attainment of the $i^{\text {th }} \mathrm{DL}, \beta_{E i}$ - corresponding fraction of the residual shear strength, with respect to $V_{y}$ ).

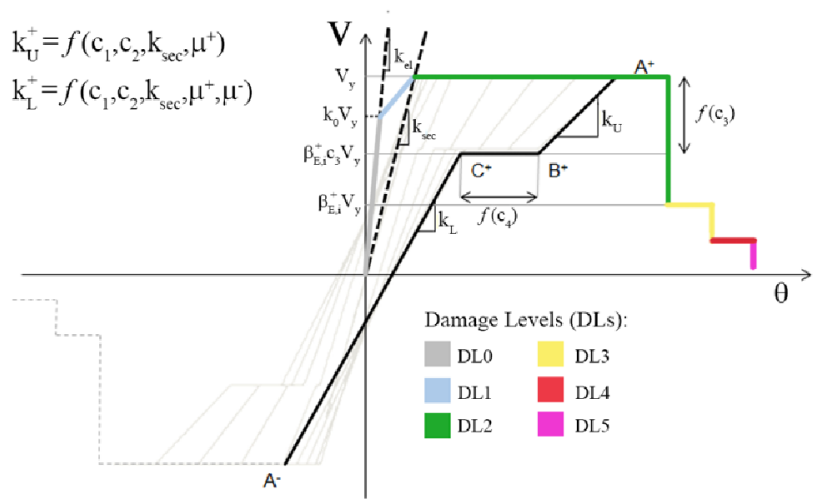

a)

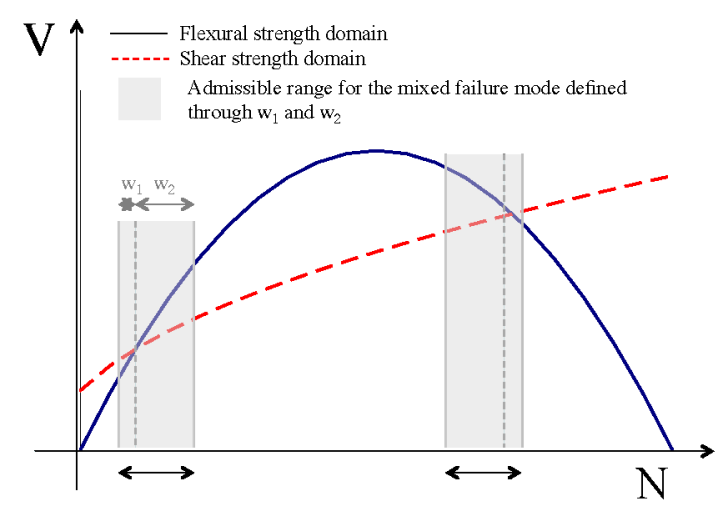

b)

Figure 1: a) Piecewise-linear constitutive law and hysteretic response of $N L B E A M$ model; b) schematic representation of the criteria assumed to define the occurrence of a hybrid failure

The elastic phase is described according to the beam theory by defining the elastic Young $(E)$ and shear $(G)$ moduli; then the progressive degradation is computed in an approximate way by a secant stiffness by assigning a proper ratio $\left(k_{r}\right)$ between the initial $\left(k_{e l}\right)$ and secant $\left(k_{\text {sec }}\right)$ stiffness, at the point in which the maximum strength 
is reached, and a ratio $\left(k_{0}\right)$ between the shear at the end of the elastic phase and the shear strength (Figure 1a). In particular, values equal to 1.6 and 0.7 were assumed for $k_{r}$ and $k_{0}$ in case of masonry piers $\left(k_{0}=0.5\right.$ for spandrels); such assumptions are compatible with the experimental evidences from Morandi et al. (2016, 2018), in the case of piers, and from Beyer and Dazio (2012), in the case of spandrels.

The maximum strength of the panel $V_{y}$ is computed as the minimum between the possible failure criteria evaluated on the basis of the current axial force acting on the element at each step; consequently, the hysteretic response of the element is based as well on currently governing failure criterion.

The different values of $\theta_{E, i}$ and $\beta_{E, i}$ are assigned for describing a prevailing flexural or shear response of the panel and may be differentiated in the case of spandrel and pier elements. For the hybrid failure mode, average values for $\theta_{E, i}$ and $\beta_{E, i}$ are computed by the program starting from those assigned by the user in the case of the basic flexural or shear failure modes. The occurrence of a hybrid mode is then established by assigning in input a given admissible range in the $V-N$ domain (close to the points in which the flexural and shear domains intersect with one another, as illustrated in (Figure 1b).

Then, a second set of parameters describes the hysteretic response, by defining the slope of unloading and loading branches of the hysteresis loops ( $\mathrm{c}_{\mathrm{i}}$ coefficients with $\left.i=1 . .4\right)$.

Table 1 summarizes the parameters adopted in NLDA. It is possible to observe how the drift limits of piers at DLs 3 and 4 correspond to those calibrated on the basis of the experimental tests available in the literature (see section 2.3). In particular, for simulating the progressive softening phase under shear failure, a sudden $40 \%$ strength degradation is assumed at DL3 drift limit and a very limited residual strength (20\%) occurs at DL4 drift limit and is maintained until DL5 (actual collapse), conventionally assumed at a drift of $0.7 \%$. In the case of flexural failure, a reduction of $20 \%$ is considered at DL4, because for this mechanism the strength degradation is less marked and occurs close to the actual collapse (DL5). The parameters adopted for the hysteretic response were calibrated based on experimental results (Magenes et al. 2008, Beyer and Dazio 2012).

Some numerical validations of the model are illustrated in (CNR DT 212 2013, Cattari et al. 2014, Marino et al. 2016) through the comparison with experimental campaigns on shaking table or with the actual response of URM buildings affected by seismic events. 
Table 1. Parameters adopted for piers and spandrels in the case of piecewise-linear constitutive law.

\begin{tabular}{|c|c|c|c|c|c|c|c|c|}
\hline \multirow{3}{*}{ Pier/Spandrel } & \multicolumn{4}{|c|}{ SHEAR (S) } & \multicolumn{4}{|c|}{ FLEXURAL (F) } \\
\hline & \multicolumn{2}{|c|}{$\begin{array}{c}\text { Backbone } \\
\text { curve }\end{array}$} & \multicolumn{2}{|c|}{$\begin{array}{c}\text { Hysteretic } \\
\text { response }\end{array}$} & \multicolumn{2}{|c|}{ Backbone curve } & \multicolumn{2}{|c|}{ Hysteretic response } \\
\hline & $\begin{array}{c}\theta_{i, S} \\
{[\%]}\end{array}$ & $\begin{array}{l}\beta_{E, i} \\
{[\%]}\end{array}$ & $c_{1}$ & $0.8 / 0.2$ & $\begin{array}{l}\theta_{I, F} \\
{[\%]}\end{array}$ & $\begin{array}{c}\beta_{E, i} \\
{[\%]}\end{array}$ & $c_{1}$ & $0.9 / 0.2$ \\
\hline DL3 & $0.24 /^{(*)}$ & $0.6 / 0.7$ & $c_{2}$ & $0.8 / 0$ & $0.6 / 0.6$ & 1 & $c_{2}$ & $0.8 / 0$ \\
\hline DL4 & $0.54 / 0.4$ & $0.2 / 0.7$ & $c_{3}$ & $0 / 0.3$ & $\begin{array}{c}1.22 / 0 \\
8\end{array}$ & $0.85 / 0.7$ & $c_{3}$ & $0.6 / 0.3$ \\
\hline DL5 & $0.7 / 0.7$ & $0 / 0$ & & & $1.6 / 1.2$ & $0 / 0$ & $c_{4}$ & $0.5 / 0.8$ \\
\hline
\end{tabular}

\subsection{Macroelement model}

The second model adopted is the macroelement proposed by Bracchi et al. (2018), which represents an improved version of the macroelement proposed by Penna et al. (2014a). The adopted element reproduces the cyclic nonlinear behavior associated with the two main in-plane masonry failure modes, bending-rocking and shear mechanisms, by means of a limited number of degrees of freedom (8) and internal variables describing the damage evolution. The axial and flexural behavior of piers and spandrels is modeled by two interfaces located at the element ends and made of a distributed system of zero-length springs with no-tension and limited compression capacity. They allow for representing the effects of cracking and toe-crushing as well as the coupling of axial displacements and rotations, including uplift of piers due to rocking motion with the associated variation of axial force.

In addition to geometrical characteristics, the macroelement is defined by eight parameters representative of an average behavior of the masonry panel: density $\rho$, elastic modulus in compression $E$, shear modulus $G$, compressive strength $f_{m}$, equivalent initial shear strength (i.e. cohesion) $c_{\text {eff }}$, global equivalent friction coefficient $\mu_{\text {eff }}$, and two coefficients $\beta$ and $c_{t}$. The parameter $\beta$ governs the slope of the softening branch of the nonlinear shear model, whereas the parameter $c_{t}$ represents the non-dimensional shear deformability. Depending on the macroscopic cohesive behavior, the amplitude of the inelastic displacement component in the force-displacement relationship is proportional to the product $G c_{t}$ (Figure 2). 

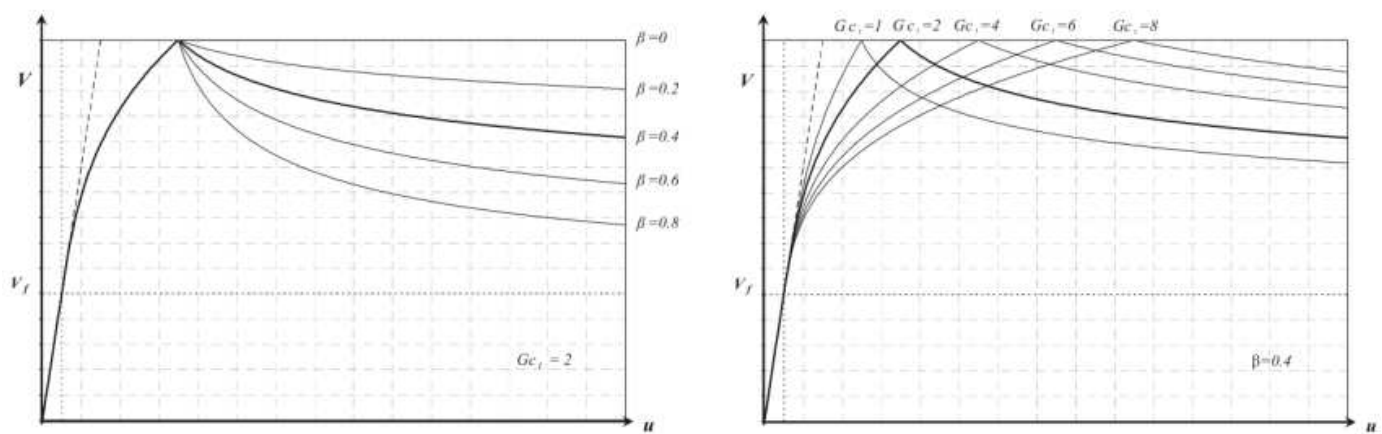

Figure 2: Role of parameters $\beta$ (left) and $c_{t}$ (right) on the shape of the nonlinear shear model (Penna et al. 2014a).

The improved version of the macroelement model solves some of the limitations of the previous element; in particular, this element is characterized by:

- a different constitutive law governing the cyclic axial behavior of the zero-length springs at the macroelement interfaces, allowing to better reproduce the energy dissipation associated with rocking mechanisms with toe-crushing;

- the introduction of an automatic nonlinear correction of the spring elastic properties for updating of the bending stiffness of each element with the variation of boundary conditions, without altering its axial stiffness;

- the possibility of considering multiple shear strength criteria with automatic calibration of the equivalent model parameters $c_{\text {eff }}$ and $\mu_{\text {eff }}$ governing the macroscopic shear damage model, starting from the "local" mechanical parameters (obtained from characterization tests or code prescriptions);

- the possibility of calibrating the shear deformability parameter $c_{t}$ to ensure that, for each element, the peak shear strength is attained at a predefined level of drift.

\subsection{Strength criteria and cross-calibration of the two considered constitutive models}

For the evaluation of the peak strength of panels in case of shear failure, the definition of the model parameters was carried out according to the Mann and Muller (1980) theory. This formulation is based on the two main hypotheses that units are much stiffer than mortar joints and mechanical properties of head joints are negligible. In case of failure along mortar joints, these hypotheses lead to a Coulomb-type criterion, based on the use of an equivalent cohesion $(\tilde{c})$ and an equivalent friction coefficient $(\tilde{\mu})$, taking into account the geometrical characteristics of the masonry bond. The adopted values for the equivalent parameters were the same mean 
values used in the design phase $\left(\tilde{c}=\mathrm{f}_{\mathrm{v} 0}=0.29 \mathrm{MPa} ; \tilde{\mu}=0.4\right)$. Indeed, these values are lower than those representative of local parameters (mortar joint), because they are already reduced to account for masonry bond.

In case of failure across units, the conventional limit shear strength introduced by the Italian code $\left(f_{v t}\right)$ was replaced by the criterion proposed by Mann and Muller (1980), that explicitly includes the tensile strength of units $\left(f_{b t}\right)$, assumed equal to $1.14 \mathrm{MPa}$ (i.e. equal to $1 / 10$ of the compressive strength of units):

$V_{R, \text { shear units }}=\frac{A f_{b t}}{2.3 b} \sqrt{1+\frac{\sigma_{0}}{f_{b t}}}$

with $A$ transversal section of panel, $\sigma_{0}$ mean normal stress acting on the gross section, $b$ corrective factor that accounts for the actual shear stress distribution in the central transversal section, here introduced in analogy to what has been done in Turnsek and Sheppard (1980).

The strength associated with the flexural failure mode was evaluated with the same approach used in the design phase, neglecting the tensile strength of the material and, in the piecewise linear model, assuming a stress block normal distribution at the compressed toe (as proposed in NTC08 and EN1998-3, 2005). For the masonry compressive strength $\left(f_{m}\right)$, a value equal to $6.66 \mathrm{MPa}$ was adopted.

The contribution of spandrels has been considered only for "C" and "I" buildings by adopting the same strength criteria used for the design, based on the development of a strut mechanism due to the presence of a coupled r.c. tie beam. Indeed, experimental evidences showed the development of a strut mechanism (Beyer and Dazio 2012, Parisi et al. 2014), although with an inclination not always consistent with the one adopted by NTC08, that tends to reduce the effective span of the r.c. tie beam. However, experimental tests are still too limited to justify the adoption of capacity models alternative to the one used for the design.

For nonlinear dynamic analyses, more refined constitutive laws were adopted in the simulations, in terms of stiffness degradation, strength deterioration and cyclic hysteretic behavior.

This required a review of the experimental data available in the literature for clay block masonry, to calibrate the constitutive laws and, in particular, drift limits and strength degradation parameters. Table 2 summarizes the median values of drift thresholds used as a reference point for the calibration of the adopted constitutive laws. They were derived from processing of data reported in Magenes et al. (2008), Morandi et al. (2016) and Petry and Beyer (2014) and refer to the case of URM panels composed by hollow clay blocks and cement mortar. 
Usually, experimental tests refer to the attainment of a $20 \%$ loss in peak strength assumed as "ultimate state". However, in some cases, tests were performed until higher drift levels, to provide information on a more severe damage state, called "near collapse" in the table. The table reports values for the case of either shear or flexural failure modes. In case of hybrid failure modes, experimental tests suggest the adoption of intermediate drift limits. It is useful recalling that the ultimate element drift thresholds assumed by NTC 08 are $0.4 \%$ and $0.8 \%$ for the shear and flexural failure modes, respectively. Considering that such values were adopted as reference for the Life Safety Limit State design, it results that these conventional values are higher than the experimental limits for the shear response, while they are lower than those for the flexural response.

Such parameters refer only to piers response but have been adopted also for spandrels; experimental tests on spandrels composed by modern blocks are indeed too limited to permit meaningful statistical evaluations. It is worth noting that the uncertainty in spandrel parameters does not significantly affect the results of the analyzed buildings, since the contribution provided by r.c. tie beams in coupling piers was dominant, favoring the so-called "strong spandrels" behavior, with the nonlinearity mainly concentrated in piers. Anyhow, experimental tests (Beyer and Dazio 2012) suggest that the deformation capacity of spandrel elements considerably exceeds that of piers.

Table 2. Data adopted as a reference for the calibration of constitutive laws of masonry piers.

\begin{tabular}{|c|c|c|}
\hline Shear failure mode $[\%]^{(+)}$ & Flexural fai & Flexural failure mode $[\%]^{(++)}$ \\
\hline $20 \%$ peak strength loss & $20 \%$ peak strength loss & near collapse ${ }^{(*)}$ \\
\hline 0.24 & 1.22 & 1.6 \\
\hline $\begin{array}{l}{ }^{(++)} \text {mainly derived from } \mathrm{I} \\
{ }^{(+)} \text {The collapse conditic } \\
20 \% \text { peak strength loss, }\end{array}$ & $\begin{array}{l}\text { ived from Magenes et al. (2008) and Morandi et a } \\
\text { Beyer (2014) } \\
\text { available and thus it was conventionally assumed } \\
\text { d in Eurocode 8-3 (2005), to pass from significant } \\
\text { state }\end{array}$ & $\begin{array}{l}\text { the displacement at } \\
\text { to near collapse limit }\end{array}$ \\
\hline
\end{tabular}

The mechanical properties adopted in the two considered constitutive models were calibrated to fit the average behavior from experimental evidence and, consequently, to obtain consistent cyclic lateral response for the structural elements. The nonlinear shear deformability parameter of the macroelement model, $G c_{t}$, was calculated at each step of the analysis and for each element, to guarantee that the peak shear strength is reached at a drift equal to the mid-point of the constant shear branch of the NLBEAM model. To select appropriate values of the parameter $\beta$, cyclic analyses were performed on four piers, realized with the same material properties adopted in the building models and fixed-fixed boundary conditions, but characterized by different 
in-plane aspect ratios $(h / l)$ and failure mechanisms (Figure 3).

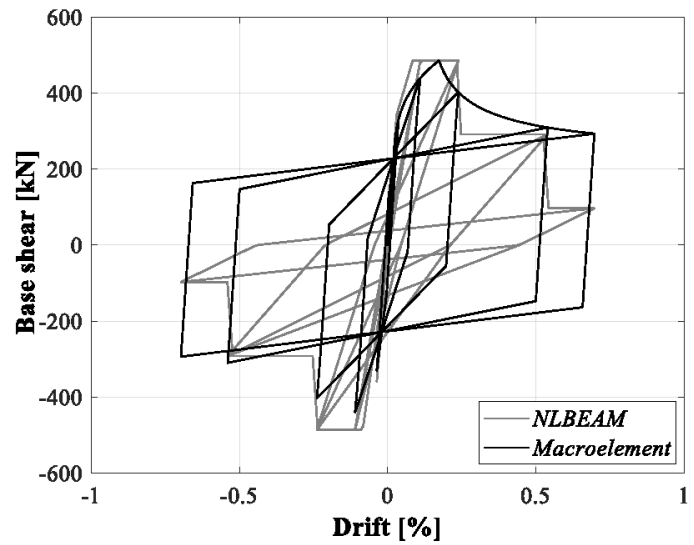

(a)

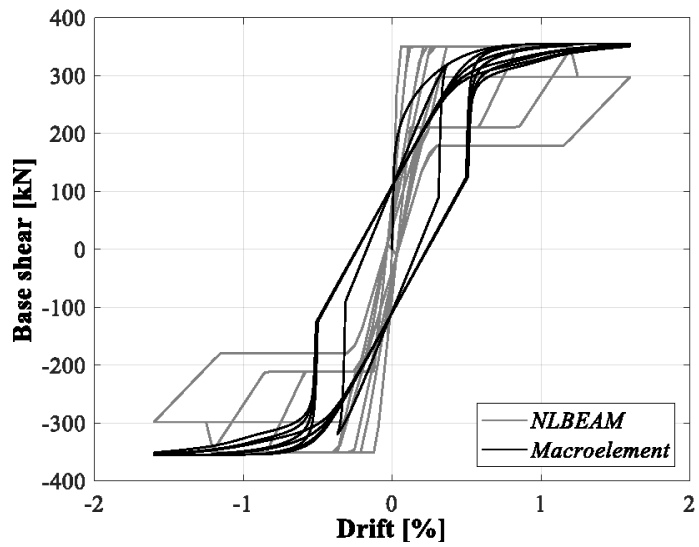

(c)

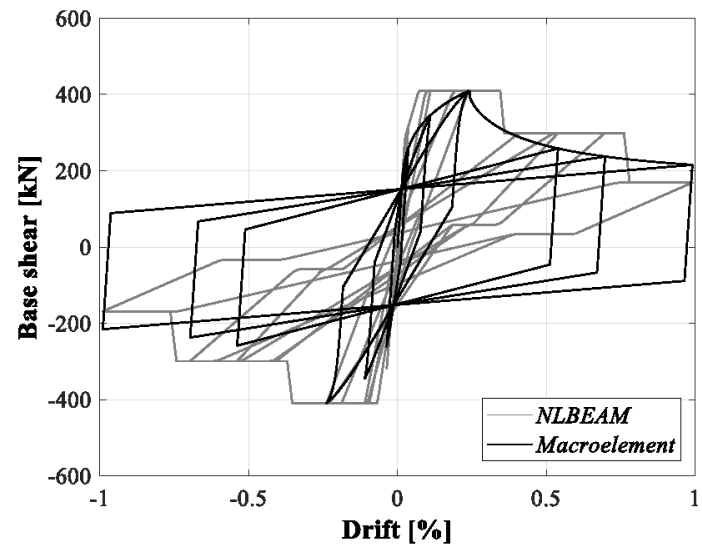

(b)

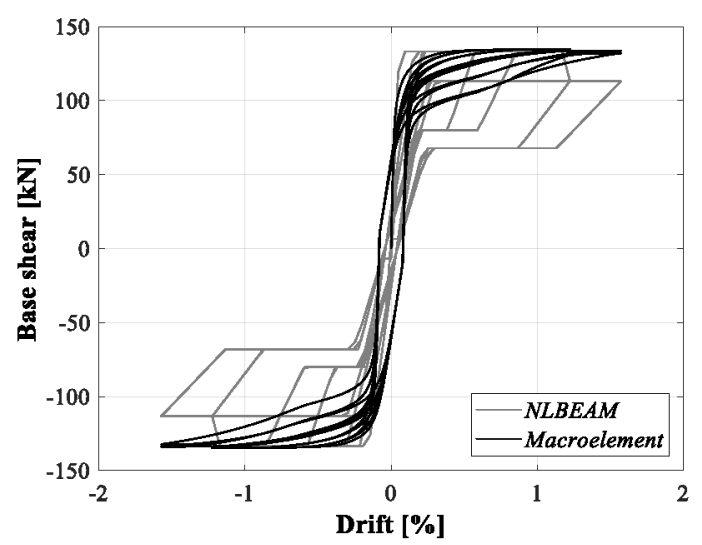

(d)

Figure 3: Base shear vs. drift curves of the four considered panels: squat panel $(h / l=0.77)$ with shear failure (a), squat panel with hybrid failure (b), squat panel with flexural failure (c) and slender panel ( $h / l=1.25$ ) with flexural failure (d). Panels are subjected to an overburden stress equal to $6.3 \%$ of masonry compressive strength for (b) and (d), $9.5 \%$ for (a) and $4.6 \%$ for (c).

Among these panels, two were designed to exhibit a flexural failure mode, one a purely shear failure mode and the last one a hybrid flexural-shear behavior. The calibration of $c_{t}$ was performed automatically, whereas the values of $\beta$ were assumed equal to 0.9 in all the cases. This value of $\beta$ allows the softening branch of the macroelement model to pass through the value of a $20 \%$ decay after the peak shear strength, at a drift corresponding to the first strength decay of the NLBEAM model. The overestimation of the strength decay with the macroelement in case of panel (b) is related to the necessity of selecting a single value of $\beta$ for all the panels: in particular, it was decided to use a value leading to the best representation of the strength decay in case of a pure shear failure, instead than of a hybrid mechanism. For the $N L B E A M$ constitutive law, it is evident 
that, in the case of the hybrid mode (Figure 3b), the hysteretic response is intermediate between the flexural pure mode (Figure 3c) and the shear pure mode (Figure 3a).

The two adopted constitutive models have pros and cons, in simulating the actual shear behavior of masonry panels. For example, the macroelement is able to model the progressive stiffness degradation before the maximum strength and the gradual softening branch, but it is less accurate in simulating the hybrid failure modes. On the contrary, the $N L B E A M$ is coarse in the shear-drift backbone curve. Regarding the cyclic hysteretic dissipation, the macroelement tends to slightly overestimate it in the case of shear failure and to underestimate it in the flexural behavior. However, it is more effective than the NLBEAM in considering the interaction between static and kinematic generalized variables, in particular the uplift that occurs due to flexural partialization at the end sections.

The two cross-calibrated models were alternatively adopted for performing the time-history analyses that consider only the record-to-record variability effect (whose results are illustrated in section 4). In particular, the macroelement model was used for the analysis of the E-type building configurations, while the NLBEAM model for the C- and I- type configurations. Conversely, both models were used to investigate the effect of the structural modelling uncertainty on the C-type configurations (section 5). It is worth noting that the dispersion obtained by adopting the two constitutive models on the same building configuration is equivalent to (or even higher than) that due to uncertainty in material properties. This means that, on one hand, design/assessment results obtained in real practice with a single constitutive model are rather conventional, while, on the other hand, the trustworthiness of the assessment is still an open issue, in the absence of an accurate calibration.

\section{Definition of Limit States}

Several criteria are proposed in literature and codes for a quantitative definition of limit states (LS). In general, they may be classified analyzing the scale they monitor. A criterion based on the local scale tracks the damage evolution of single structural elements, or of a set of structural elements; a global criterion is usually based on checks on the pushover curve evolution (e.g. associated to the attainment of given percentage of the overall base shear). At an intermediate scale, it is usually related to the in-plane behavior of each wall. Each scale requires, on the one hand, the identification of proper Engineering Demand Parameters (EDPs), to monitor the 
response evolution and, on the other, the definition of proper thresholds, to verify the attainment of the corresponding limit conditions.

While codes usually refer to the adoption of a single criterion (that may also vary passing from a LS to another), recent literature studies showed that a most reliable evaluation is obtained by considering a combination of several criteria (e.g. Mouyiannou et al. 2014, Lagomarsino and Cattari 2015, Kappos and Papanikolaou, 2016, Marino et al. 2018); all of them explicitly consider criteria particularized for the case of nonlinear time-history analyses.

The criteria adopted in the RINTC project for URM buildings combine the will to adopt consistent criteria across the different structural typologies examined (i.e. URM, reinforced concrete, steel, etc...) and the evidences from the most up-to-date researches, with some simplifications allowed by the specific features of modern URM buildings. The selected EDP is the maximum inter-story drift $\left(\theta_{\max }\right)$ assessed at the wall scale, that is defined as $\theta_{\max }=\max \left(\theta_{w, l}\right)$ where $w$ and $l$ refer to the wall number and level number, respectively. It was computed by accounting for the contribution of both horizontal displacement and rotation (Lagomarsino and Cattari 2015), even though the latter has a limited role in the examined structures, due to the presence of rigid slabs and systematic r.c. tie beams. Considering the possible different behavior of the buildings in the two directions, the maximum inter-story drift was evaluated separately for each direction $\left(\theta_{\max , X}\right.$ and $\left.\theta_{\max , Y}\right)$, since all walls were parallel to the main building axes. The selection of this EDP, commonly adopted in codes and in the literature, is motivated by the presence of rigid diaphragms and r.c. tie beams promoting a global behavior, governed by the in-plane response of walls, with the development of story mechanisms (Tomazevic, 1987).

This expected behavior limits the significance of checks performed on single structural elements (piers), for the identification of global failure modes, which may be instead identified with direct reference to the inter-story drift. Moreover, considering the maximum value among all the walls - instead of an average value at the floor level - allows to identify local concentration of damage induced, for example, by torsional effects due to irregularity in plan.

Further details on the criteria adopted for the two performance conditions considered in the assessment are described in the following sections. It is useful pointing out that the meaning of two limit states considered in the design and assessment phases is different. While in the design phase, as illustrated in Manzini et al. 
(2018), rigorous reference was made to the limit states adopted by codes (i.e. the Life-safety and Damage Limitation limit states), the two performance conditions considered in this study refer to structural performance levels, to which a physical meaning can be clearly associated.

\subsection{Global Collapse limit state}

The reference thresholds of $\theta_{\max , X(Y)}$ for the GC limit state were defined by means of pushover analyses carried out in the two perpendicular directions ( $\mathrm{X}$ and $\mathrm{Y}$ ), considering different load patterns (mass-proportional and inverse triangular) in both positive and negative orientations of seismic actions . For each analysis, the GC condition was identified as the one corresponding to a $50 \%$ post-peak deterioration of the total base shear of the building and the maximum inter-story drift among all walls in the direction of analysis at all stories was recorded. The minimum values over all the analyses in each direction were then assumed as the GC limit state thresholds, $\left(\theta_{G C, X}\right.$ and $\left.\theta_{G C, Y}\right)$, specific for each examined structure. The collapse limit state function $Y_{G C}$ was then evaluated as:

$$
Y_{G C}=\max \left(\frac{\theta_{\max , X}}{\theta_{G C, X}} ; \frac{\theta_{\max , Y}}{\theta_{G C, Y}}\right),
$$

with $\theta_{\max , X}$ and $\theta_{\max , Y}$ maxima inter-story drifts in the two directions recorded during the time-history analysis.

\subsection{Usability-Preventing Damage limit state}

The attainment of the UPD limit state was identified by the multi-criteria approach defined consistently for all structural typologies, as discussed in Iervolino et al. (2018).

The definition of the UPD thresholds was based on pushover analysis, considering the inverse triangular load pattern, which is the one able to represent well the response until reaching the maximum strength. The attainment of the first among the three criteria listed below was identified on the obtained pushover curves:

A. $50 \%$ of masonry piers (in terms of resistant area) reached the condition of light/moderate damage;

B. one masonry pier reached a severe damage condition (drift threshold corresponding to DL3, as indicated in Table 1, for the NLBEAM-model or attainment of the toe-crushing or shear failure condition for the macroelement model); 
C. the base shear has reached the $95 \%$ of the peak resistance.

In any case the final threshold should be associated to a value of the base shear not lower than $85 \%$ of the peak resistance. This lower bound is justified by the fact that URM buildings may show slight but widespread damage even for values of the base shear far from the peak value.

Regarding the criterion $\mathrm{A}$, for the $N L B E A M$ model, the condition of light/moderate damage corresponds to DL2 (peak strength, Figure 1a), whereas, for the macroelement model, this condition corresponds either to the attainment of the peak shear strength of the pier, or to flexural cracking.

For each examined building, this procedure led to the definition of two thresholds in the two main directions $\left(\theta_{U P D, X}\right.$ and $\left.\theta_{U P D, Y}\right)$, obtained as the minimum between the positive and negative direction. Then, similarly to the GC limit state, the UPD limit state function $Y_{U P D}$ can be evaluated according to the following equation:

$$
Y_{U P D}=\max \left(\frac{\theta_{\max , X}}{\theta_{U P D, X}} ; \frac{\theta_{\max , Y}}{\theta_{U P D, Y}}\right)
$$

\subsection{Limit state thresholds for the examined buildings}

The application of the criteria previously discussed to the buildings whose design is illustrated in Manzini et al. (2018) provided the values of the EDP thresholds reported in Table 3. The variability in the reported values is obviously related to the specific architectural layout of the different buildings, but also to the adopted constitutive model (NLBEAM model was used for "C" and "I" configurations, macroelement model for "E" configurations).

Regarding the definition of the thresholds for the UPD limit state, it is observed that in most cases the dominant check resulted to be the lower bound equal to $85 \%$ of the peak resistance. In case of NLBEAM model, the condition associated to criterion A occurred for values of the base shear approximately between $65 \%$ and $90 \%$ of the peak strength, due to the significant diffusion of slight damage in the piers not only at the ground story but also at the upper stories, with a flexural failure mode. This failure mode can be justified by the low (in relation to the compressive strength of masonry) rates of compression characterizing the pier panels, especially in the case of 2-story configurations. For the considered cases, criterion B never governed. 
Table 3. Values of EDP thresholds [in \%] for the considered buildings, in the two main directions. Irregular configurations are identified by the symbol *.

\begin{tabular}{cccccccccc}
\hline \multicolumn{4}{c}{ 2 stories } & \multicolumn{6}{c}{3 stories } \\
\hline Building & $\theta_{U P D, X}$ & $\theta_{U P D, Y}$ & $\theta_{G C, X}$ & $\theta_{G C, Y}$ & Building & $\theta_{U P D, X}$ & $\theta_{U P D, Y}$ & $\theta_{G C, X}$ & $\theta_{G C, Y}$ \\
\hline C1 & 0.0313 & 0.0187 & 0.885 & 1.161 & $\mathrm{C} 1$ & 0.0411 & 0.0299 & 0.784 & 1.223 \\
C2 & 0.0301 & 0.0176 & 0.784 & 1.162 & $\mathrm{C} 2$ & 0.0373 & 0.0273 & 0.773 & 1.191 \\
$\mathrm{C} 3$ & 0.0179 & 0.0141 & 0.705 & 1.154 & $\mathrm{C} 3$ & 0.0338 & 0.0223 & 0.628 & 1.034 \\
$\mathrm{C} 4$ & 0.0179 & 0.0141 & 1.077 & 1.154 & $\mathrm{C} 4$ & 0.0344 & 0.0214 & 0.627 & 0.983 \\
$\mathrm{C} 7$ & 0.0154 & 0.0136 & 0.946 & 1.153 & $\mathrm{C} 5$ & 0.0295 & 0.0196 & 0.629 & 1.156 \\
& & & & & $\mathrm{C} 6$ & 0.0298 & 0.0189 & 0.680 & 0.914 \\
E2 & 0.182 & 0.177 & 1.236 & 1.502 & $\mathrm{E} 2$ & 0.269 & 0.240 & 1.485 & 1.472 \\
E8 & 0.096 & 0.156 & 1.647 & 0.916 & $\mathrm{E} 8$ & 0.243 & 0.172 & 1.109 & 0.657 \\
E9 & 0.372 & 0.086 & 1.026 & 0.514 & $\mathrm{E} 9$ & 0.351 & 0.083 & 0.861 & 0.265 \\
$\mathrm{I} 1^{*}$ & 0.0265 & 0.0179 & 1.081 & 0.377 & $\mathrm{I} 2^{*}$ & 0.0247 & 0.0193 & 1.283 & 0.917 \\
E5* & 0.099 & 0.1320 & 0.716 & 1.204 & $\mathrm{E} 5 *$ & 0.059 & 0.080 & 0.743 & 0.622 \\
\hline
\end{tabular}

Figure 4 shows, for two of the examined buildings (C4-3 Stories and E5-3 Stories), the pushover curves obtained through the application of the inverse triangular distribution, with the indication of the attainment of the two limit states.

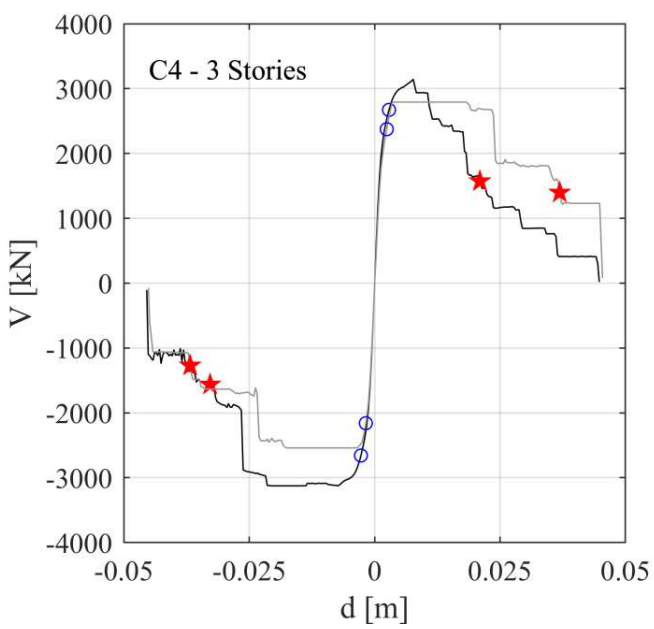

(a)

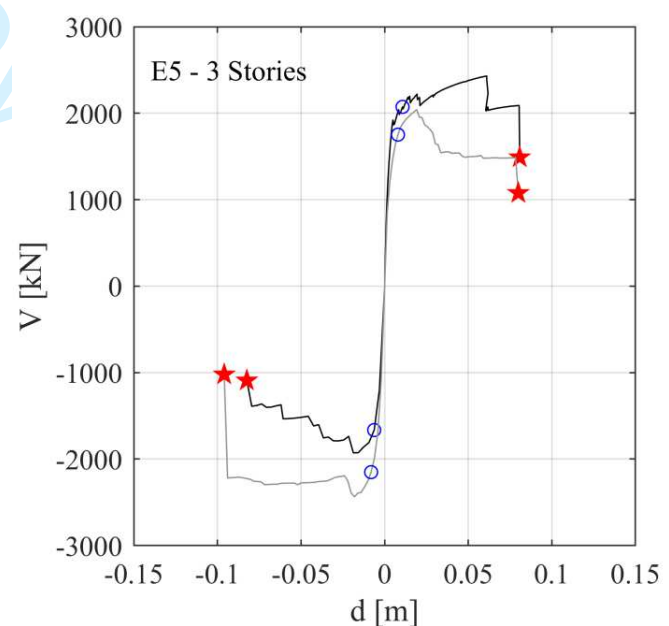

(b)

X Direction Y Direction

O UPD

Figure 4: Pushover curves (inverse triangular load pattern) for two of the selected building configurations (C4 - 3 stories (a) and E5 - 3 stories (b)), with identification of the thresholds of UPD (blue circles) and GC (red stars). 


\section{Time-History Analyses of the Selected Building-Site Combinations}

Nonlinear dynamic analyses were performed using a multi-stripe approach, with records selected for 10 values of return period of the seismic action at each site, ranging from 10 to 100,000 years, as discussed in detail in Iervolino et al. (2018).

A Rayleigh viscous damping model was adopted. The coefficients multiplying the mass and damping matrices were determined by assuming a viscous damping equal to 0.03 in a significant range of periods around the fundamental ones.

Figure 5 shows, for some selected building-site combinations and for a given direction, the obtained hysteretic curves in terms of total base shear ( $V_{X}$ or $V_{Y}$, for $X$ and $Y$ directions, respectively) versus a representative displacement at the roof level $\left(d_{X}\right.$ or $\left.d_{Y}\right)$, obtained by weighting nodes displacements by their tributary masses. In particular, for a given stripe, the two time-histories (THs) inducing the maximum and the minimum displacement demand are shown.

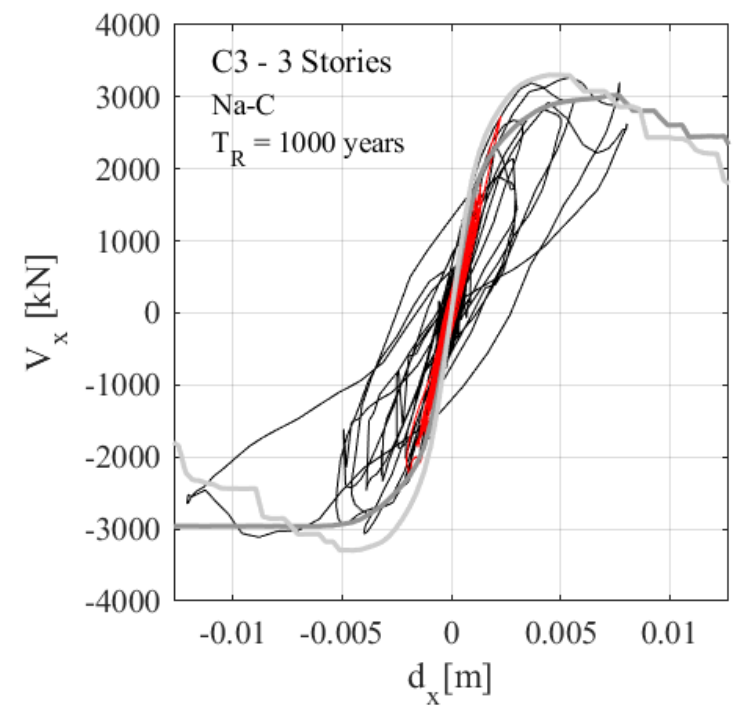

(a)

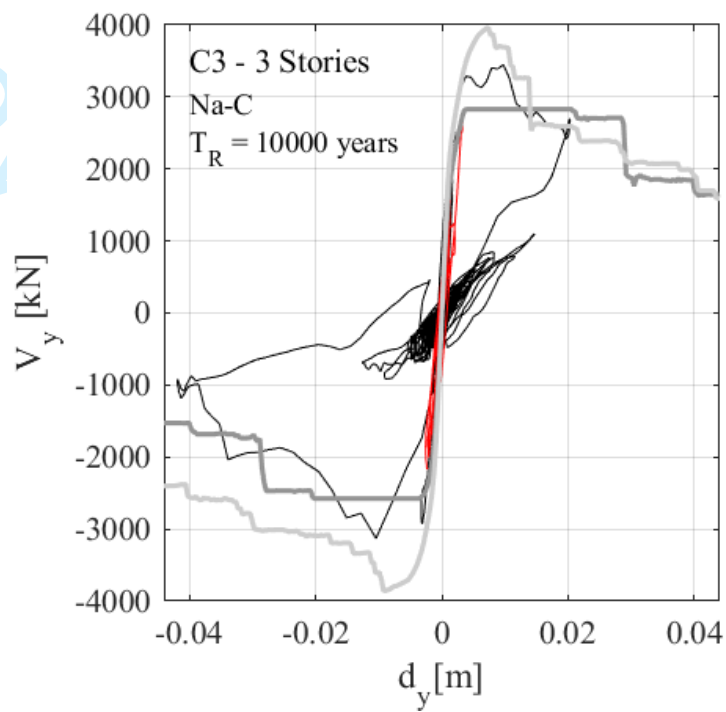

(b) 


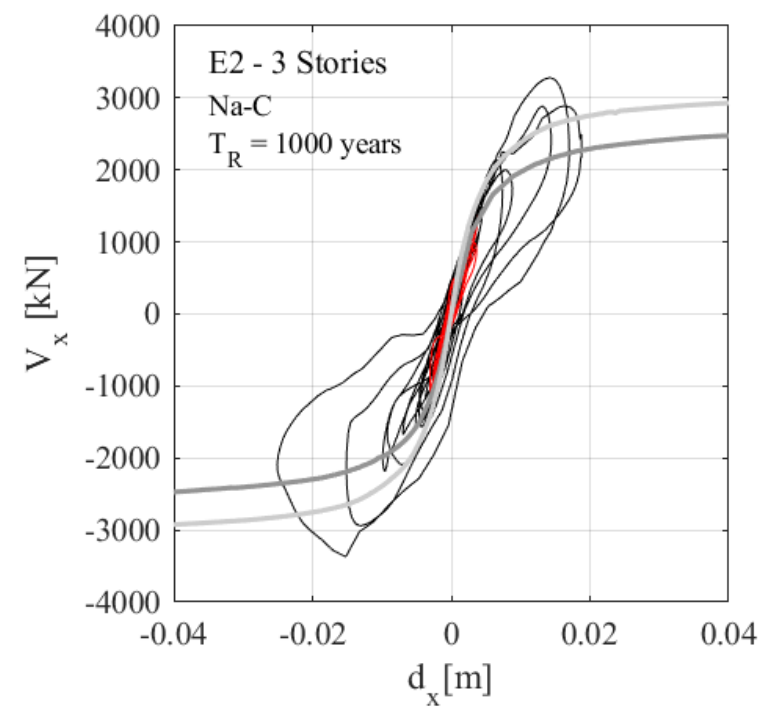

(c)

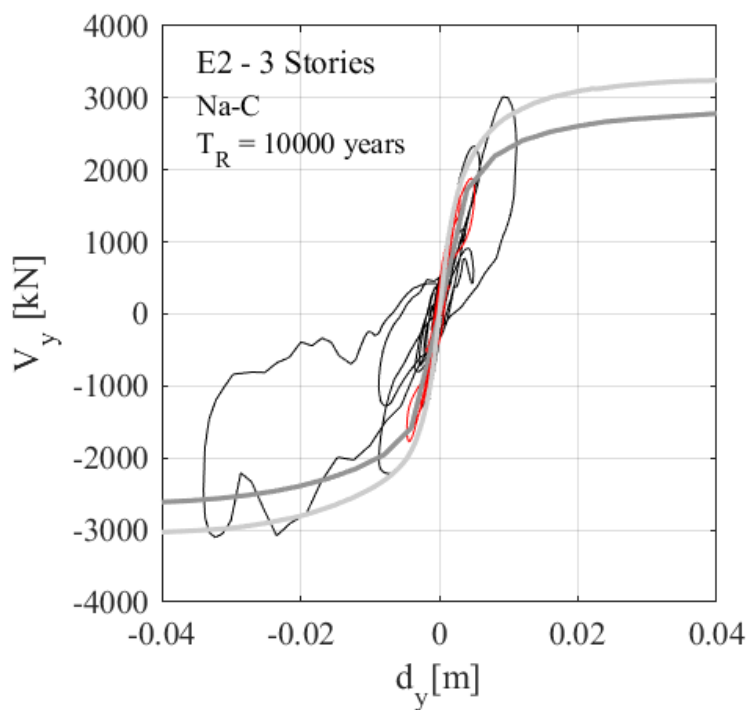

(d)

NLDA - TH $_{\max } \longrightarrow$ NLDA - TH $d_{\min } \longrightarrow$ NLSA Triangular $\longrightarrow$ NLSA Uniform

Figure 5: Hysteretic cycles and corresponding pushover curves for 2 different buildings located in Naples, soil type C. For each stripe, red curves correspond to time history providing minimum displacement demand, black curves to time history providing maximum displacement demand.

It can be observed that the constitutive laws adopted allow to obtain stable results, even when the response of the structure becomes significantly nonlinear. This is particularly evident in Figure 5 passing from the hysteretic response for a return period $T_{R}=1000$ years $\left(6^{\text {th }}\right.$ stripe) $(\mathrm{a}, \mathrm{c})$ to that associated to $T_{R}=10000$ years $\left(9^{\text {th }}\right.$ stripe) (b,d).

The analysis of the damage pattern allows the identification of the predominant failure mode in each building configuration.

Considering both the regular "C" - 3-story configurations and the irregular "I" buildings (both 2 and 3 stories) analyzed with the NLBEAM-model, the prevailing global failure mode resulted to be a soft-story mechanism at the ground level, typically with a shear failure in the squattest piers and flexural failure in the slender ones. This global failure mode is justified by the presence of rigid diaphragms and r.c. tie beams at each story, which contribute to activate a strong spandrel-weak pier behavior. It is recalled that, as discussed in Manzini et al (2018), in the "C" and "I" configurations the spandrels, coupled with r.c. tie beams, provide a constraint to the rotations of the end sections of the adjacent piers. Furthermore, the presence of rigid diaphragms promotes a global behavior of the building with the attainment of a quite homogeneous damage level in all piers of the different walls. Figure 6 shows the damage pattern characterizing two walls of the C1-3 story configuration, 
produced by different THs of the same stripe. From this figure it can be seen that, despite the record-to-record variability (already highlighted in Fig.5), in general the damage level in the piers is higher than that reached in the spandrels. Furthermore, it can be clearly observed the activation of a soft-story mechanism at the ground level, which represents the recurrent collapse mechanism for "C" buildings.

For the "E" configurations (Figure 7) analyzed with the macroelement model, a typical global cantilever behavior was observed, with the activation of a prevailing flexural response of the masonry piers. This mechanism is mainly motivated by the fact that, in these buildings, spandrels are not present, thus resulting in a low degree of constraint to the rotations of the end sections of the piers. It is worth highlighting that the DL color associated in Figure 7 to the pier panels refers to the activation of the shear response, which is measured by means of an internal shear damage variable (always equal to zero in the cases shown in Figure 7).
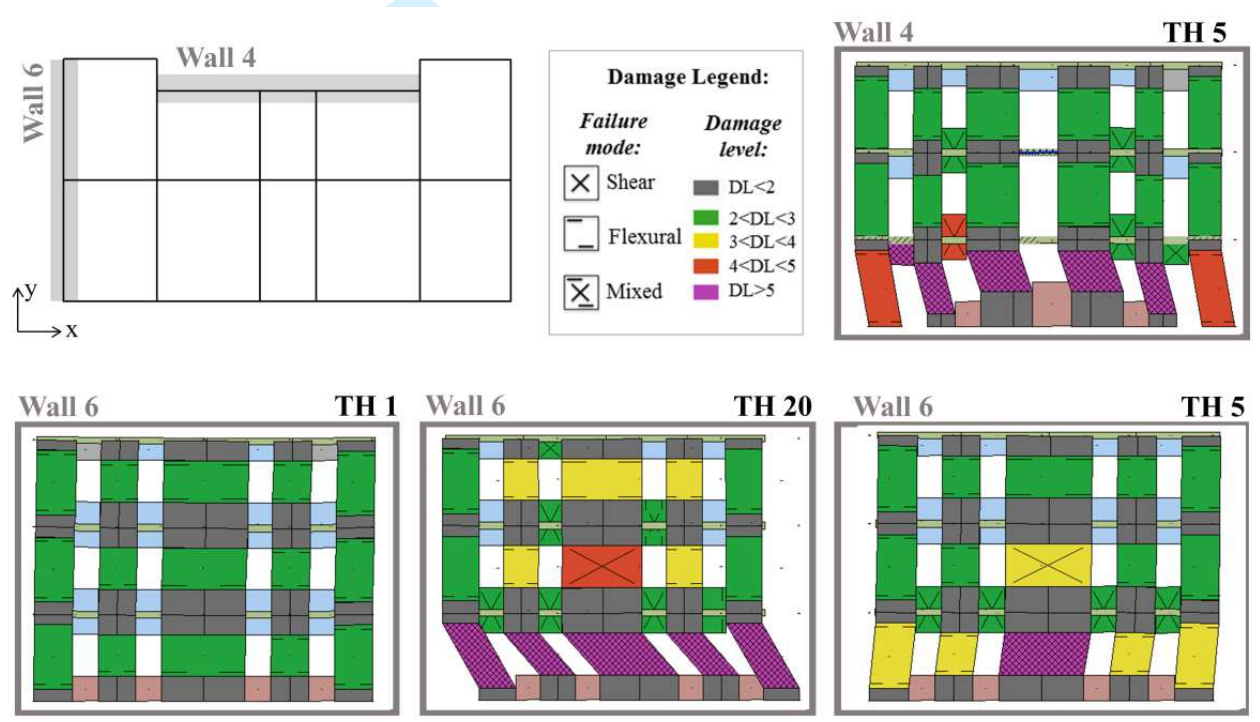

Figure 6: Damage occurred in two different walls (wall $6-Y$ direction and wall 4- $X$ direction) of the $\mathrm{C} 1-3$ stories configuration analyzed in L'Aquila (soil type A) with the NLBEAM-model, as a consequence of different TH of stripe 6. 


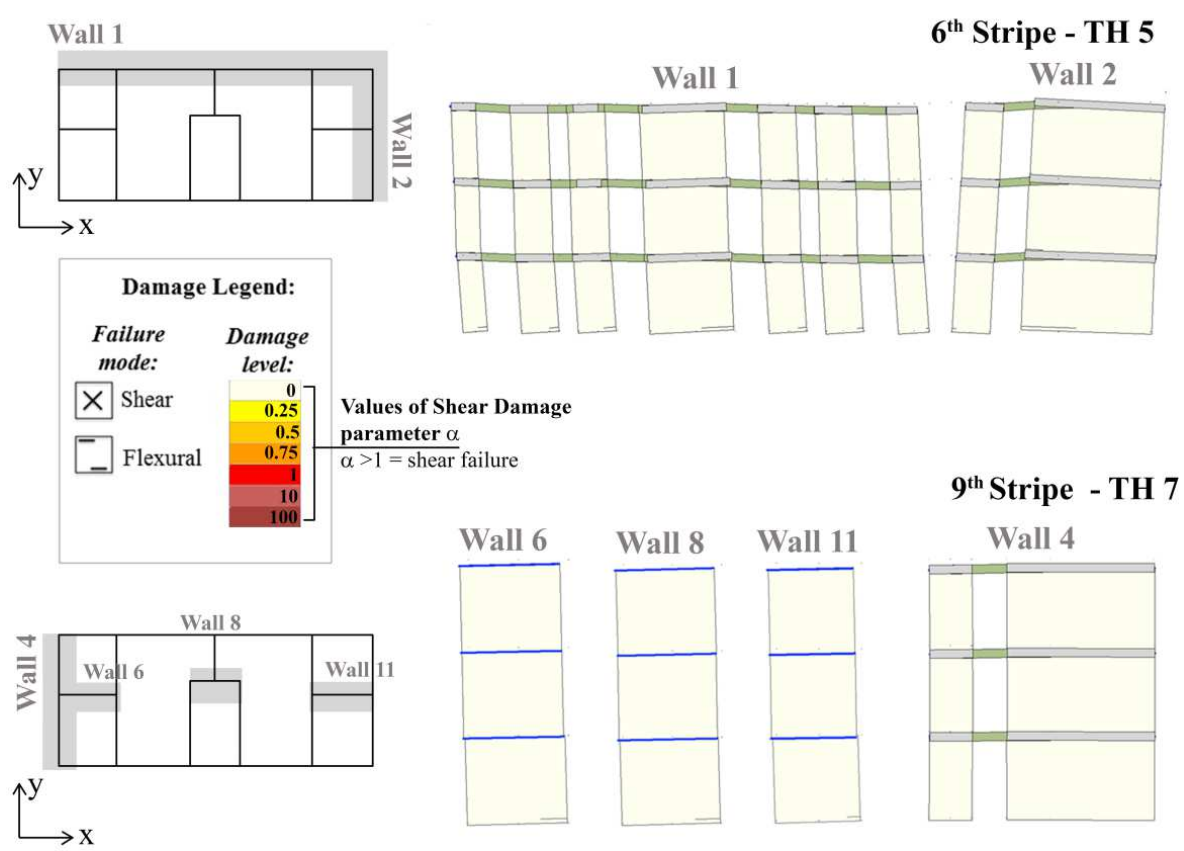

Figure 7: Damage occurred in some walls of E2- 3 stories configuration analyzed in L'Aquila (soil type A) with the macroelement-model, as a consequence of two different THs belonging to the 6th and 9th stripes, respectively.

The results of NLDA are shown in terms of IM- $Y_{L S}$ curves, reporting on the vertical axis the value of the Intensity Measure (IM), in this case the spectral acceleration at $T_{1}=0.15 \mathrm{~s}$, and on the horizontal axis the value of the limit state variable $Y_{L S}$ (i.e. $Y_{G C}$ or $Y_{U P D}$ ), corresponding to given fractiles of the probability density function of the $Y_{L S}$ values obtained from the nonlinear dynamic analyses performed for each stripe. In particular, the median and the $16^{\text {th }}$ and $84^{\text {th }}$ percentiles of the results of each stripe are indicated by the continuous and dashed lines, respectively.

In the case of $Y_{U P D}$, a lognormal distribution was assumed, while for the global collapse the procedure adopted to define the IM- $Y_{G C}$ curves is illustrated in Figure 8. For the stripes characterized by the higher values of IM, among the twenty $Y_{G C}$ values associated to each record, some of them could be obtained from an analysis which cannot be considered anymore representative of the actual physical behavior of the building (e.g.: i) the residual total base shear is close to zero, as assumed for the "C" and "I" configurations; ii) the $Y_{G C}$ value is conventionally assumed as unrealistically high) or even the $Y_{G C}$ value is not available, due to dynamic instability during the analysis (this event occurred in very few cases, for some configurations). These cases are conventionally named "Collapse Cases" (CC) (Iervolino 2017) and the corresponding contribution to the probability of global collapse is $P_{C C}=N_{C C} / 20$, where $N_{C C}$ is the number of CC. The remaining values of $Y_{G C}$ were assumed distributed according to a lognormal distribution, and the obtained probability density function 
was multiplied by $\left(1-P_{C C}\right)$, in order to combine the two contributions to the total probability. When a certain probability of overcoming $P$, given IM, is considered (namely $0.16,0.5$ and 0.84 ), the corresponding value $Y_{G C P}$ is obtained by selecting the fractile (1-P)/(1-PCC) in the lognormal probability density function of $Y_{G C}$ obtained from the $\left(1-N_{C C}\right)$ analyses without $\mathrm{CC}$. It is worth noting that each IM- $Y_{G C, P}$ curve becomes flat when $P_{C C}=P$; therefore, the point cannot be evaluated if $P_{C C}>P$. Considering, for example the median IM- $Y_{G C}$ curve

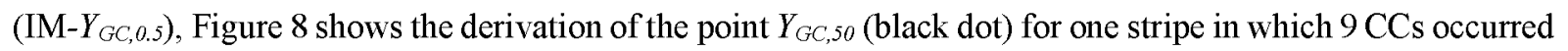
$\left(P_{C C}=0.45\right)$ : the fractile of the lognormal distribution obtained from the other 11 analyses is then 0.909 .

The final IM- $Y_{G C, P}$ curve is the piecewise linear interpolation of the different stripes processed in that way. The value of the IM associated to the GC $\left(\mathrm{IM}_{\mathrm{GC}, \mathrm{P}}\right)$ is then obtained from the intersection with $Y_{G C}=1$. Other methods for treating CCs (analyses for which the EDP value is not available or unrealistically high, with respect to the ones observed in real buildings before collapse) are illustrated in Iervolino (2017).

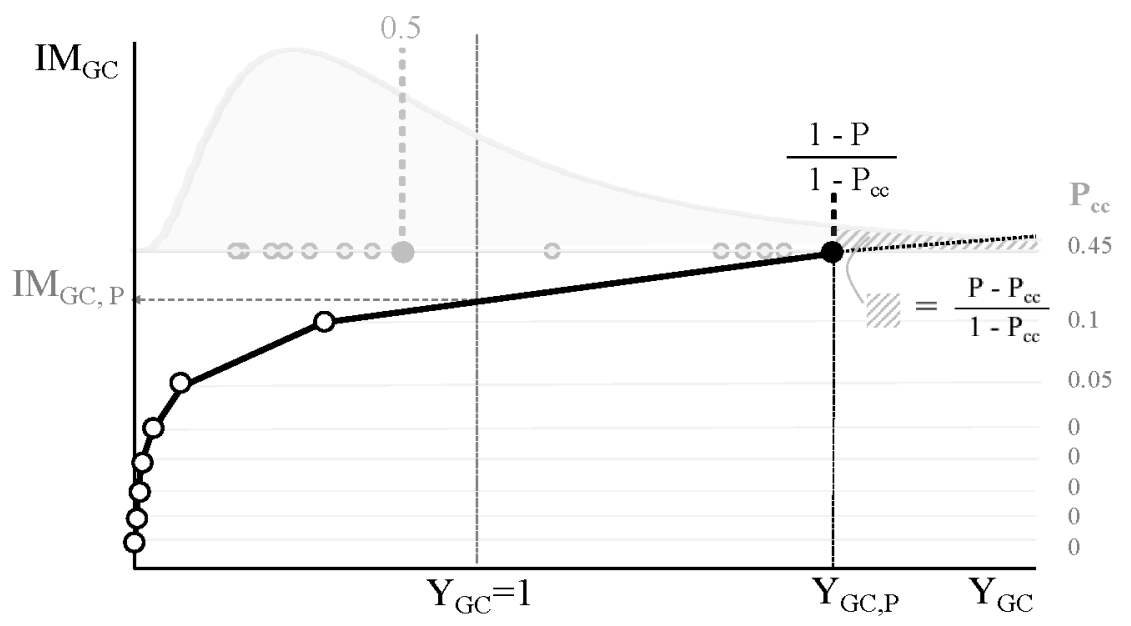

Figure 8: Exemplification of the calculation adopted for including the collapse cases in the IM- $Y_{G C}$ curves, for a given probability of overcoming $P$.

Figures 9,10 and 11 illustrate the IM- $Y_{L S}$ curves corresponding to the $16^{\text {th }}, 50^{\text {th }}$ and $84^{\text {th }}$ fractiles obtained for some of the examined building-site combinations together with the outcomes (gray dots, in which CCs are not included) of each performed dynamic analysis. Figure 9 reports the results for different regular "C" configurations, analyzed with the $N L B E A M$-model at different sites and resulting from the adoption of various design methods, as illustrated in Manzini et al. (2018). However, the results reported in Figure 9 show that the safety level obtained for the different sites with the different configurations is not homogeneous, as for example the attainment of the GC condition never occurred in Milan, whereas it occurred for a return period between 
$T_{R}=10000$ years and $T_{R}=100000$ years in Naples and it occurred for a period between $T_{R}=2500$ years and $T_{R}=5000$ years in L'Aquila.

\section{Mi - Soil type C C2 -3 stories (SB)}
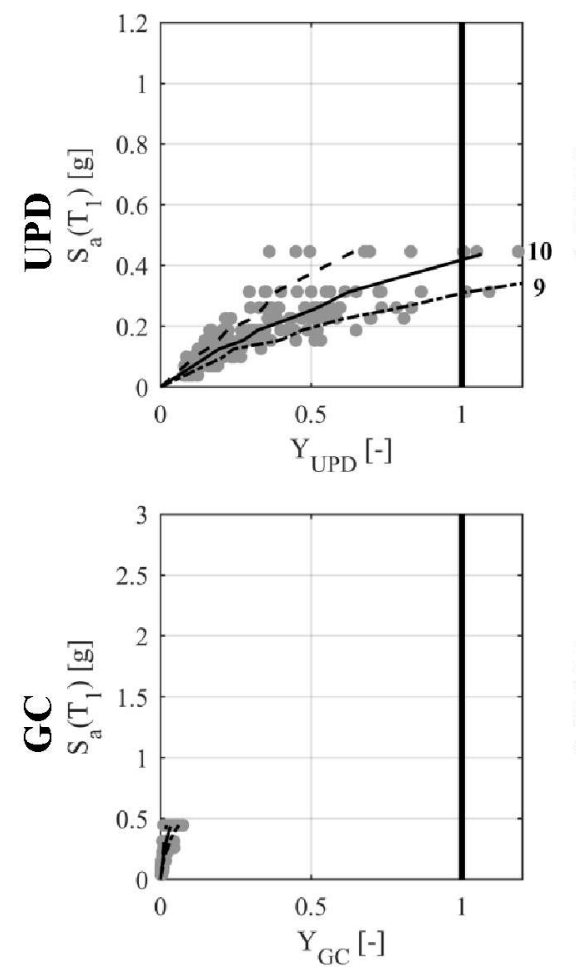
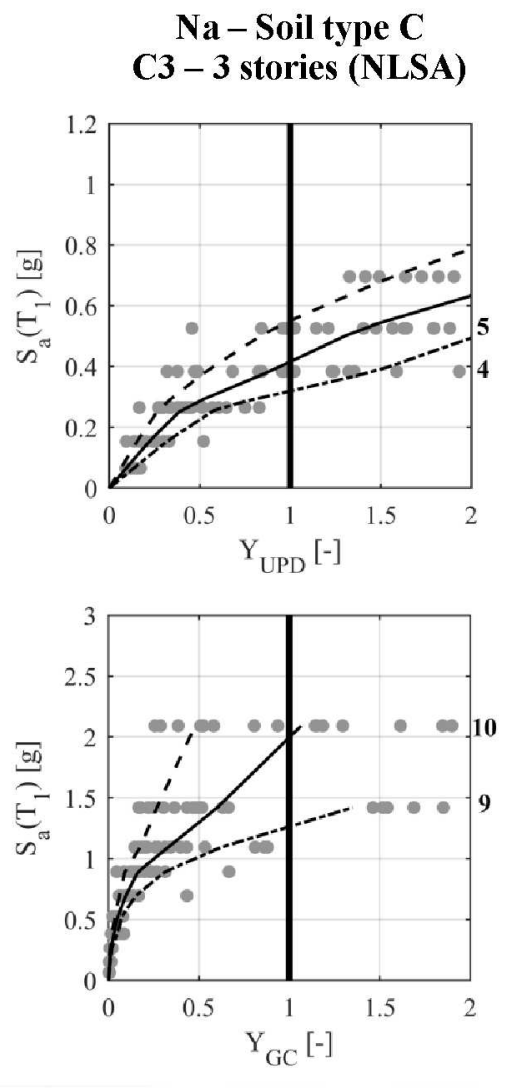

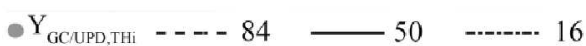

Aq - Soil type C C3- 2 stories (NLSA)
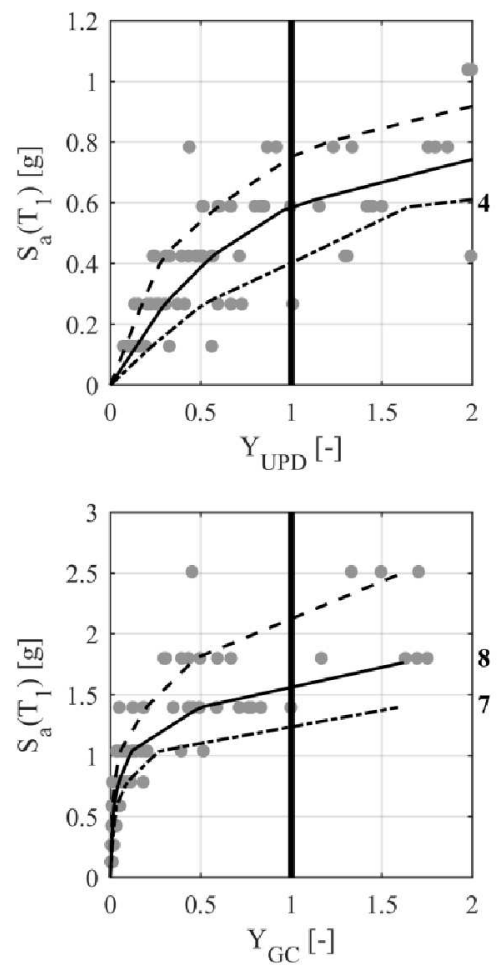

Stripe $\left[\mathrm{n}^{\circ}\right]-\mathrm{T}_{\mathrm{R}}$ [years] conversion: $1-10 ; 2-50 ; 3-100 ; 4-250 ; 5-500 ; 6-1000 ; 7-2500 ; 8-5000 ; 9-10000 ; 10-100000$

Figure 9: Results of NLDA for different C-type building-site combinations: median (continuous line) and $16^{\text {th }}$ and $84^{\text {th }}$ percentiles (dashed lines) of the results for each return period, for the UPD (top) and the GC (bottom) limit states. The vertical line indicates the attainment of the limit state $(\mathrm{Y}=1)$ and the bold numbers on the right of each subplot refer to the stripe number.

Figure 10 shows the results for the E2 3-story building, analyzed with the macroelement model. This configuration was verified using different methods. It resulted to barely comply with code requirements at different sites, depending on the selected method (Manzini et al. 2018). Figure 10 shows that the attainment of the GC limit state $\left(Y_{G C}=1\right)$ was not reached in Milan with any of the considered THs, it occurred in six cases in Naples (for $T_{R}=100000$ years) and it was reached for several cases starting from a return period of $T_{R}=1000$ years in L'Aquila. Similarly, the UPD condition was never reached in Milan, whereas it was reached starting from a return period of $T_{R}=500$ years in Naples (soil C) and from $T_{R}=1000$ years in L'Aquila. 
These results confirm that LSA provides an over-conservative design, more than the application of SB rules, which represent the most simplified design approach allowed by NTC08 for URM structures and thus the one for which in principle should provide the highest level of conservativeness.

Moreover, by comparing the IM- $Y_{L S}$ curves obtained for the E2 - 3 stories configuration in L'Aquila and in Naples it is observed that they are influenced (for a fixed value of IM) by the different selection of the THs for these two sites, which result more demanding for the given structure in the case of L'Aquila, in particular for the GC limit state. This seems to be consistent whit the fact that the selected THs can differ in terms of duration and other significant parameters depending on the specific characteristics of the seismic hazard.
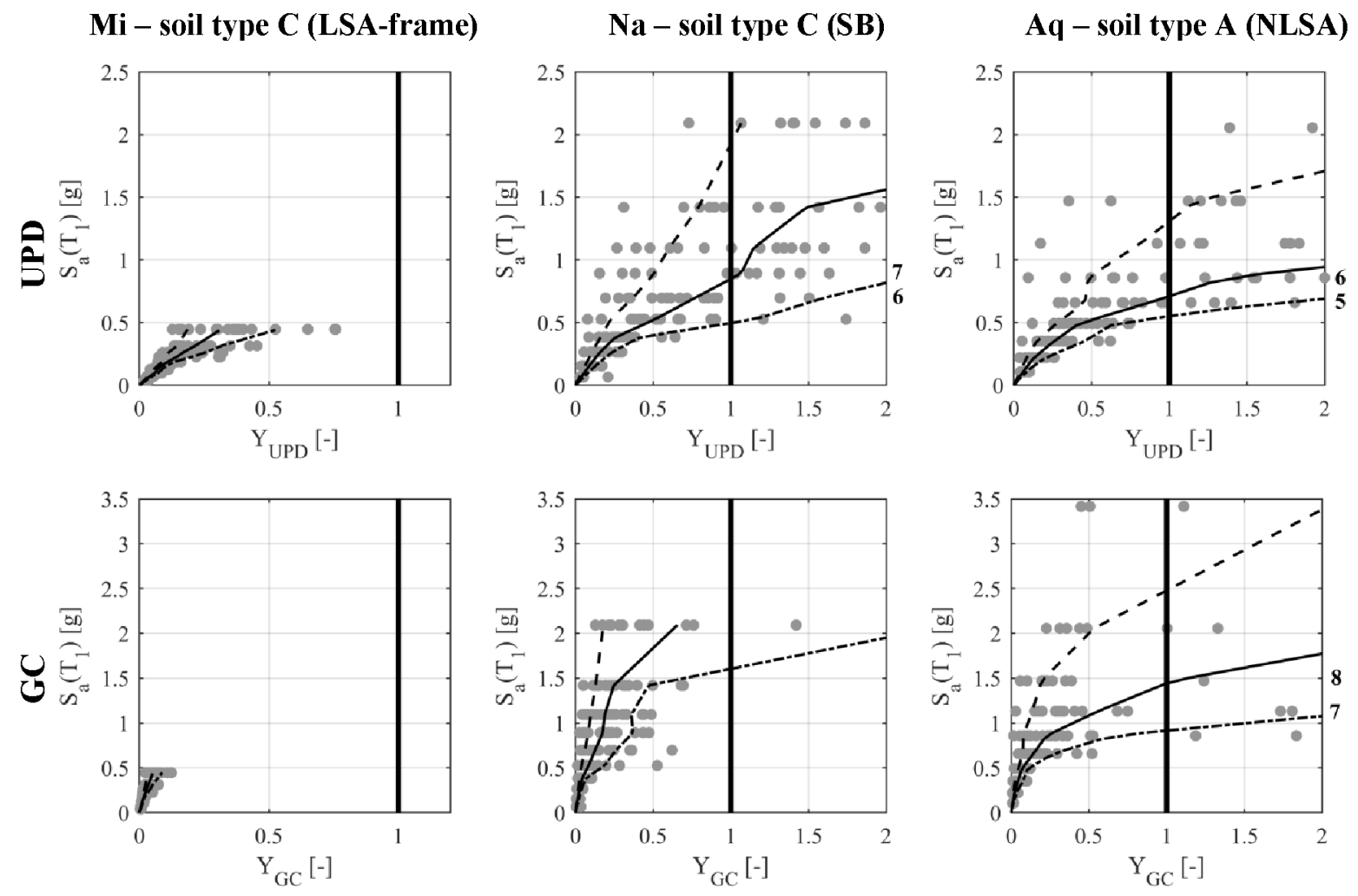

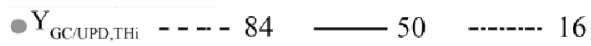

Stripe $\left[n^{\circ}\right]-T_{R}$ [years] conversion: $1-10 ; 2-50 ; 3-100 ; 4-250 ; 5-500 ; 6-1000 ; 7-2500 ; 8-5000 ; 9-10000 ; 10-100000$

Figure 10: Results of NLDA for the same building (E2-3 story), that was designed using different methods (into brackets) at different sites (Manzini et al. 2018): median (continuous line) and $16^{\text {th }}$ and $84^{\text {th }}$ percentiles (dashed lines) of the results for each return period, for the UPD (top) and the GC (bottom) limit states. The vertical line indicates the attainment of the limit state $(\mathrm{Y}=1)$ and the bold numbers on the right of each subplot refer to the stripe number.

The significant conservativeness inherent to the Linear Static Analysis (LSA) method is confirmed also in the case of the irregular E5 2-story configuration in Milan, as illustrated in Figure 11, which reports the same type 


\section{Aq - Soil type C (NLSA)} I1- 2 stories
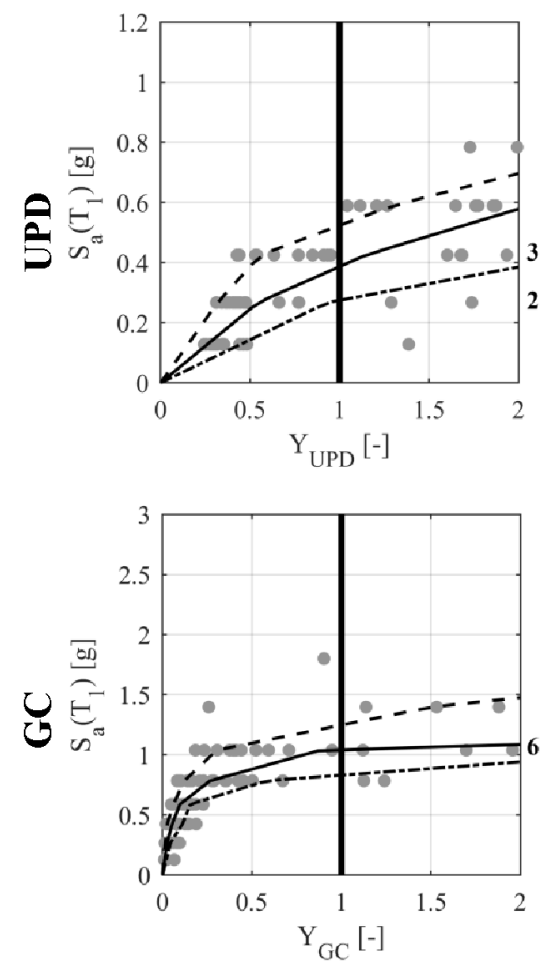

- $\mathrm{Y}_{\mathrm{GC,NPD}, \mathrm{THi}}----84$
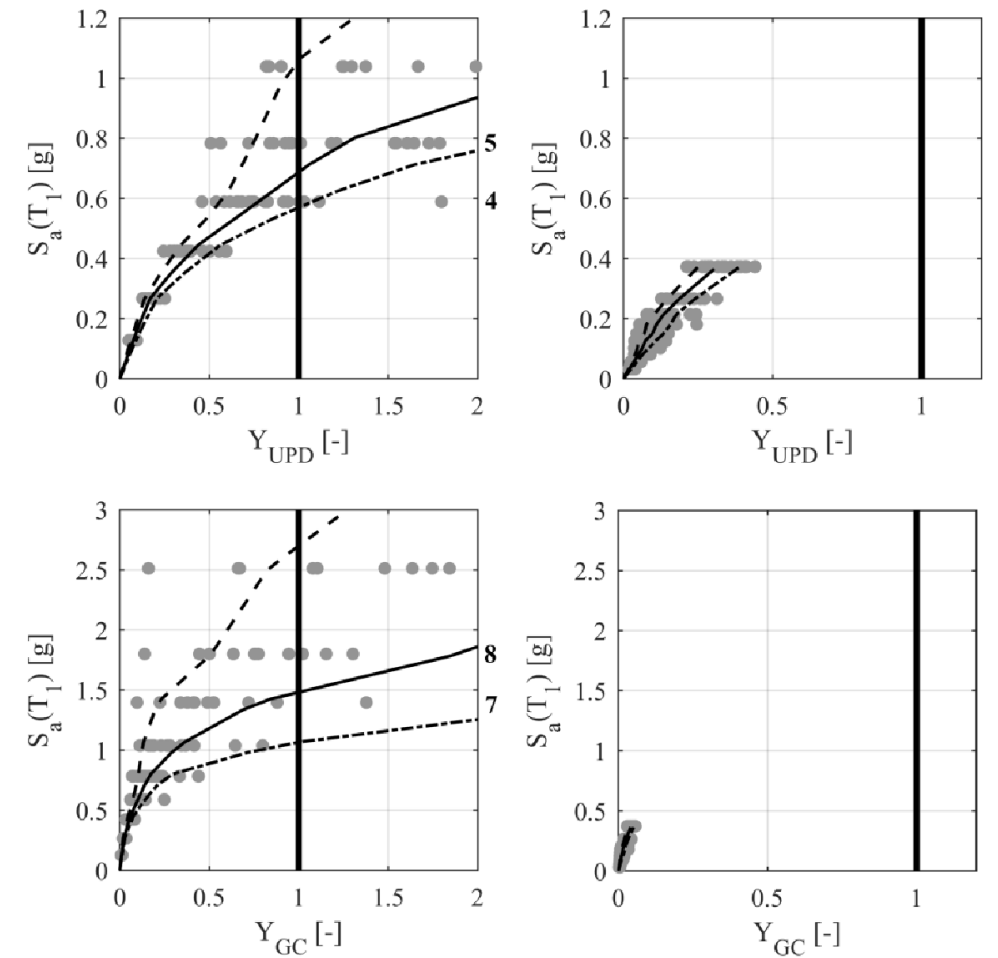

Stripe $\left[\mathrm{n}^{\circ}\right]-\mathrm{T}_{\mathrm{R}}$ [years] conversion: $1-10 ; 2-50 ; 3-100 ; 4-250 ; 5-500 ; 6-1000 ; 7-2500 ; 8-5000 ; 9-10000 ; 10-100000$

Figure 11: Results of NLDA for different irregular building-site combinations: median (continuous line) and $16^{\text {th }}$ and $84^{\text {th }}$ percentiles (dashed lines) of the results for each return period, for the UPD (top) and the GC (bottom) limit states. The vertical line indicates the attainment of the limit state $(Y=1)$ and the bold numbers on the right of each subplot refer to the stripe number.

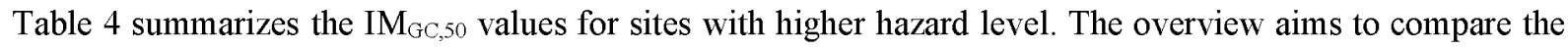
obtained vulnerability for the 2 and 3 -story buildings and to calculate the ratio $\mathrm{IM}_{\mathrm{GC}, 50} / \mathrm{IM}_{\mathrm{UPD}, 50}$, which 
represents a sort of behavior factor, that should not be mistaken with the behavior factor $q$ in codes, being the former higher than the latter for the following reasons: i) it refers to GC and not to the Life Safety limit state, ii) UPD limit state occurs when some masonry elements are above the elastic limit but before the maximum global shear strength (therefore a fraction of the overstrength ratio is included); iii) behavior factors in codes are conservative (fractile of values of a population of buildings), hence it is expected they are lower values with respect to single cases.

In particular, "C" and "I" configurations show in some cases high values of the ratio, mostly due to a very low

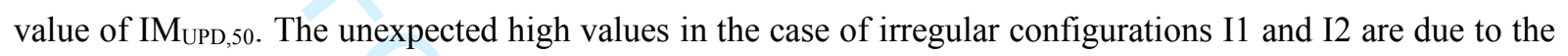
fact that torsional effects mainly affect the elastic response, thus inducing an early occurrence of the UPD limit state, but are less relevant in the nonlinear phase, when the response becomes more regular due to a widespread damage, mainly associated with a soft story mechanism at GC limit state.

Table 4 also reports the values of the safety factor $\alpha$ and the return period of the design seismic action corresponding to the Life Safety limit state $T_{R, \text { design }}$, showing that, in general, C-type configurations are more over-designed than E configurations (see also Manzini et al. 2018 for a better explanation of the reasons).

Table 4. Values of the IM (spectral acceleration at $T_{l}=0.15 \mathrm{~s}$ ) obtained from the median curve at the attainment of the GC and UPD limit states (IM $G C, 50$ and $\left.I M_{U P D, 50}\right)$, for the configurations analyzed in the sites with higher hazard levels. The table reports also values of the safety factor obtained from design (Manzini et al. 2018) and the return period of the design seismic action corresponding to the life safety limit state. The $\mathrm{agS}_{475 \mathrm{yrs}}$ factor refers to the seismic input associated to a return period of 475 years.

\begin{tabular}{lcccccc|cccc}
\hline & \multicolumn{9}{c}{ 2-story } & \multicolumn{4}{c}{ 3-story } \\
\hline Building & C3 & E2 & E8 & E9 & E5 & I1 & C3 & E2 & E8 & I2 \\
\hline Site & Aq-C & Aq-C & Aq-C & Aq-C & Aq-C & Aq-C & Na-C & Aq-A & Na-C & Na-C \\
\hline $\mathbf{a g S}_{\mathbf{4 7 5 y r s}}\left[\mathbf{m} / \mathbf{s}^{\mathbf{2}}\right]$ & $\mathbf{3 . 4 0 4}$ & $\mathbf{3 . 4 0 4}$ & $\mathbf{3 . 4 0 4}$ & $\mathbf{3 . 4 0 4}$ & $\mathbf{3 . 4 0 4}$ & $\mathbf{3 . 4 0 4}$ & $\mathbf{2 . 4 0 3}$ & $\mathbf{2 . 5 6 0}$ & $\mathbf{2 . 4 0 3}$ & $\mathbf{2 . 4 0 3}$ \\
\hline $\boldsymbol{T}_{\boldsymbol{R}, \text { design }}[\mathbf{y e a r s}]$ & 1155 & 562 & 783 & 712 & 654 & 1674 & 835 & 732 & 779 & 1589 \\
\hline $\boldsymbol{\alpha}$ & 1.22 & 1.04 & 1.12 & 1.10 & 1.08 & 1.28 & 1.19 & 1.16 & 1.14 & 1.27 \\
\hline $\mathbf{I M}_{\mathbf{G C , 5 0}}\left[\mathbf{m} / \mathbf{s}^{\mathbf{2}}\right]$ & 1.608 & 1.631 & 1.667 & 1.283 & 1.495 & 1.054 & 1.996 & 1.450 & 2.092 & 1.614 \\
\hline $\mathbf{I M}_{\mathbf{U P D}, \mathbf{5 0}}\left[\mathbf{m} / \mathbf{s}^{\mathbf{2}}\right]$ & 0.591 & 0.890 & 0.809 & 0.844 & 0.699 & 0.378 & 0.413 & 0.724 & 0.734 & 0.408 \\
\hline $\mathbf{I M}_{\mathbf{G C}, \mathbf{5 0}} / \mathbf{I M} \mathbf{M}_{\mathbf{U P D}, \mathbf{5 0}}$ & 2.721 & 1.833 & 2.061 & 1.520 & 2.139 & 2.788 & 4.833 & 2.003 & 2.850 & 3.956 \\
\hline
\end{tabular}




\section{Effect of Uncertainties on the Capacity}

The analyses described in the previous sections were carried out considering only the uncertainty related to seismic action (i.e. record-to-record variability). In this section, the effect on the results of structure-related uncertainty is investigated. In particular, such additional sources of uncertainty can be grouped into:

1) uncertainties due to the adopted method, which are related to the design/verification phase and depend on the choice of the analysis method adopted (Simple Building rules - SB, Linear Static Analysis -LSA or NonLinear Static Analysis-NLSA);

2) structural modelling uncertainties, influencing both design and analysis phases and concerning the different possible modelling choices and constitutive laws;

3) aleatory uncertainties, related to the assessment phase, and depending on the variability of mechanical properties (stiffness and strength) and ultimate displacement capacity of masonry panels (drift thresholds).

As far as the first uncertainty source concerns, as illustrated in detail in Manzini et al. (2018), in the case of the "C"-type building, different structural configurations were conceived at the same site, as resulting from the adoption of various analysis approaches. This implies that the final result in terms of risk associated with such architectural configuration could be obtained as a proper weighted average of all results achieved. The weights assigned on expert judgment basis to each design method are summarized in Table 5. The frequency with which professional engineers choose the method primarily reflects the popularity of some modelling techniques over others (e.g. frame models are in general more used than cantilever models), and also the opportunity given by their implementation in the commercial software currently used in professional practice (e.g. nonlinear static analysis is more commonly used for masonry buildings than for other typologies, such as reinforced concrete). Moreover, since, as highlighted in Manzini et al. (2018), with LSA it is very difficult to obtain configurations complying with the code requirements for the high seismic hazard sites, it may happen that in these cases a professional engineer would design with another, more successful, method. This justifies the adoption of different weights for different hazard of the sites as proposed in Table 5 by way of example in the case of Rome and L'Aquila. 
Table 5. Probability attributed to the different analysis methods considered (SB - Simple Buildings rules; LSA - Linear Static Analysis; NLSA - NonLinear Static Analysis)

\begin{tabular}{|c|c|c|c|}
\hline Site & SB & LSA & NLSA \\
\hline AQ & $40 \%$ & $5 \%$ & $55 \%$ \\
\hline RM & $60 \%$ & $15 \%$ & $25 \%$ \\
\hline
\end{tabular}

The following sections describe in detail the other categories of uncertainty and explain how all of them were accounted for in the performed analyses. Then, section 6 illustrates some of main results achieved, with reference to the site of L'Aquila soil type A, selected as an example, for 2- and 3-storey C-type configurations.

\subsection{Identification of structural modeling uncertainties}

Structural modeling uncertainties, intended as uncertainties in the building's numerical model, play an important role in the evaluation of the seismic response of masonry buildings (e.g. Rota et al. 2014). The main sources of uncertainty related to modelling assumptions have to do with the choice of the analysis methodology (static vs. dynamic, linear vs. nonlinear analysis) and the modelling approach (e.g. finite elements, macroelements, etc...). This aspect was investigated in detail in several literature works, with reference to structural typologies different from masonry buildings whereas, to the authors' knowledge, only very few studies analyzed the effect of modelling uncertainties on the response of masonry structures (e.g. Parisi and Augenti, 2012, Bracchi et al. 2015, Cattari et al. 2015, Bosiljkov et al. 2015, Bartoli et al. 2017).

As already introduced in Manzini et al. (2018), in this study attention was focused on the epistemic uncertainty represented by the different possible modelling choices of the engineer, when defining the structural model from the architectural configuration of the building. The following aspects were considered:

1) spanning direction of the floor and roof diaphragms;

2) effective length of r.c. tie beams;

3) degree of connection between orthogonal walls.

Referring to point 1), two modelling options were considered, i.e. unidirectional behavior, with $100 \%$ of load transferred in the principal direction of the diaphragm and partially bidirectional behavior, with $80 \%$ of the load transferred in the principal direction and $20 \%$ in the orthogonal one. This is because mixed r.c. - hollow clay tile rigid diaphragms, typically used in new masonry buildings, have a prevalent unidirectional behavior. 
However, a partially slab-like behavior can be generated, hence transferring part of the load in the secondary direction.

The effective length of r.c. tie beams should account for the more or less effective coupling between masonry panels, as also testified in the experimental work done by Beyer and Dazio (2012). In this study, r.c. tie beams were assumed to have an effective length either equal to the total length of the wall (long tie beams, "L-tb") and effective length equal to the net width of the corresponding opening (short tie beams, "S-tb").

Regarding the degree of connection between orthogonal walls, two extreme modelling options were considered, i.e. perfect connection and limited connection.

These modelling uncertainties affect the definition of the structural model and hence they influence both the design phase and the analysis phase. In the design phase, in case of NLSA, only the relevant uncertainties were considered. For equivalent frame models, all the introduced epistemic uncertainties were initially considered. Moving to the analysis phase, the designed buildings were modelled trying to reproduce as accurately as possible their actual structural response. In this case, a unidirectional behavior of the diaphragms was assumed, because preliminary analyses showed a limited influence of this parameter on the structural response of these building configurations. A perfect connection between orthogonal walls was also assumed, because, for newly designed masonry buildings, the code requires the adoption of specific structural details guaranteeing a boxlike behavior, with perfect coupling between orthogonal walls. The only relevant modelling choice considered also in the analysis phase was related to the effective length of r.c. tie beams, for which both options were considered, assuming that probably $75 \%$ of engineers would resort to L-tb (default option in many computer programs) and $25 \%$ would go for S-tb.

Table 6 summarizes the "C" building configurations resulting from the design according to the different analysis methods and modeling assumptions, with indication of the relative probability to be selected. It is worth recalling that in L'Aquila the use of LSA didn't allow to design any structural configuration compatible with requirement of Life Safety LS. 
Table 6. Summary of the results of the design phase and related frequencies considering the different design methods and the epistemic uncertainties for the site of L'Aquila (AQ-A).

\begin{tabular}{c|c|c|c|c}
\hline Design method & \multirow{2}{*}{ SB } & \multirow{2}{*}{ LSA } & \multicolumn{2}{|c}{ NLSA } \\
\cline { 4 - 5 } & & & S-tb & L-tb \\
\hline Initial engineer's choice for AQ (from Table 5) & $40 \%$ & $5 \%$ & $41.25 \%$ & $13.75 \%$ \\
\hline 2-story configurations & $\mathrm{C} 5(42.1 \%)$ & - & \multicolumn{2}{|c}{$\mathrm{C} 1(57.9 \%)$} \\
\hline 3-story configurations & $\mathrm{C} 6(42.1 \%)$ & - & $\mathrm{C} 1(43.4 \%)$ & $\mathrm{C} 3(14.5 \%)$ \\
\hline
\end{tabular}

\subsection{Uncertainties on material properties}

To account for uncertainty in material properties, several random variables were introduced, as well as a multivariate statistical model describing the correlation structure among different parameters.

A common sampling procedure was defined for all building typologies involved in the RINTC Project, as discussed in Franchin et al. (2018). This procedure allows sampling values of the mechanical properties of the different structural elements in a very efficient way, accounting for the assumed marginal probability distributions of the intra- element correlations of the structure and of the intra-building correlation.

Six random variables were considered, to take into account aleatory variability in masonry material properties, for the two considered constitutive laws. They consist in the Young's modulus (E), masonry compressive strength $\left(f_{m}\right)$, initial shear strength $\left(f_{\mathrm{v} 0}\right)$ and the three incremental drift thresholds $(\Delta \theta)$, necessary to identify the attainment of different damage conditions. In particular, three meaningful damage conditions were identified by the corresponding drift thresholds: the attainment of a post-peak $20 \%$ drop in lateral resistance for failure in shear (indicated by $\left.\theta_{3, S}\right)$ or flexure $\left(\theta_{3, F}\right)$, the attainment of a $50 \%$ drop in lateral resistance for failure in shear (indicated by $\left.\theta_{4, S}\right)$ or flexure $\left(\theta_{4, F}\right)$ and the attainment of zero residual strength $\left(\theta_{5, S}\right.$ or $\left.\theta_{5, F}\right)$. The corresponding values of drift were defined by introducing some incremental drift aleatory variables, $\Delta \theta_{3, S}$, $\Delta \theta_{4, S}$ and $\Delta \theta_{5, F}$, defined as:

- $\Delta \theta_{3, S}=\theta_{3, S}-0.001$

- $\Delta \theta_{4, S}=\theta_{4, S}-\theta_{3, S}$

- $\Delta \theta_{5, F}=\theta_{5, F}-0.002$

The lognormal functional form was selected for representing the aleatory variables describing the constitutive laws adopted for masonry. The distribution is identified by two parameters, i.e. median and dispersion, whose values for each random variable are summarized in Table 7. 
The median value of $E$ was derived by fitting a lognormal distribution to the experimental values available in the literature from tests on vertically perforated clay block masonry walls with filled head- and bed-joints (Morandi et al. 2016, Franchin et al. 2018); the value of dispersion was derived from the data. The mean value of $E$ is the same assumed in the design phase (Manzini et al. 2018). Similarly, for the masonry compressive strength, the value of dispersion was derived from experimental data and the median value was calculated by assuming a lognormal distribution and using the same mean value adopted for design.

The dispersion associated with the initial shear strength was instead assumed based on expert judgement, as the experimental available data were not sufficient to reliably identify this value. The median value was derived starting from the characteristic value used for design $\left(f_{v 0}=0.2 \mathrm{MPa}\right)$ and assuming a ratio between the characteristic and the mean value equal to 0.7 , for consistency with the assumption used for design. The median value of $f_{v 0}$ was hence derived under the assumption of lognormal distribution.

The drift thresholds were derived from cyclic shear-compression tests on clay block masonry piers (Morandi et al. 2016). These tests allowed defining the dispersion of the three considered random variables, as well as the median values of the incremental aleatory variables defined above.

Table 7. Values of median and dispersion of each considered random variable, assumed to follow a lognormal distribution function.

\begin{tabular}{l|c|c|c|c|c|c}
\hline Material property & $\boldsymbol{E}[\mathrm{MPa}]$ & $\boldsymbol{f}_{\boldsymbol{m}}[\mathbf{M P a}]$ & $\boldsymbol{f}_{\boldsymbol{v} \boldsymbol{0}}[\mathbf{M P a}]$ & $\boldsymbol{\Delta}_{\boldsymbol{3}, \boldsymbol{S}}$ & $\boldsymbol{\Delta \theta}_{\boldsymbol{4}, \boldsymbol{S}}$ & $\boldsymbol{\Delta}_{\boldsymbol{s}, \boldsymbol{F}}$ \\
\hline Median & 4517 & 6.46 & 0.27 & $0.14 \%$ & $0.27 \%$ & $1.65 \%$ \\
\hline Dispersion & 0.25 & 0.25 & 0.3 & 0.3 & 0.25 & 0.4 \\
\hline
\end{tabular}

The other material parameters required by the two considered constitutive models were assumed to be deterministically related to the considered random variables, as discussed in Manzini et al. (2018) and Franchin et al. (2018). In particular, the shear modulus was assumed equal to 0.4 times the Young's modulus, as conventionally recommended in NTC08 (2018) and in EN1996-1-1 (2004) and adopted in the design phase (Manzini et al. 2018).

The correlation structure between the different random variables, for the intra-element case, is discussed in detail in Franchin et al. (2018).

The uncertainty on material properties of the r.c. elements - i.e. the r.c. ties - was neglected, since these elements mainly affect the coupling of masonry piers, but they substantially remain in the elastic phase until 
the collapse of the buildings, as result from the analysis of the damage pattern from the nonlinear dynamic analyses (see section 4). Indeed, unless considering unrealistically low values (for a new building) for the mechanical properties of the steel reinforcement and the stirrups spacing, the uncertainty in these parameters does not affect the global structural response. Moreover, it is worth noting that the aleatory uncertainty in the elastic properties of concrete could slightly affects the coupling effect, but this effect was examined to some extent by analyzing the role of the effective length of r.c. ties (as mentioned in section 5.2).

\section{Influence of Uncertainties on the Assessment of Seismic Response}

This section illustrates the effects of the previously discussed sources of uncertainty on the seismic response of the "C" configurations.

Table 8 summarizes the resulting values of the EDP thresholds for each examined configuration, obtained taking into account the uncertainties associated with constitutive models and possible modelling choices (long or short r.c. tie beams). Median values of thresholds and corresponding dispersion calculated among the 20 models (each one defined by one realization of the set of mechanical properties in the structural elements) are reported for the $N L B E A M$-model $\left(\mu_{N L B}, \beta_{N L B}\right)$ and the macroelement model $\left(\mu_{\text {macro, }} \beta_{\text {macro }}\right)$.

Table 8. Values of EDP thresholds (inter-story drift) for the UPD and GC limit states for each examined building including the effect of uncertainty $\left(\mu_{N L B}\right.$ and $\mu_{\text {macro }}$ in [\%])

\begin{tabular}{|c|c|c|c|c|c|c|c|c|c|c|c|}
\hline & & \multirow{2}{*}{\multicolumn{5}{|c|}{ L-tb Models }} & \multirow{2}{*}{\multicolumn{5}{|c|}{ S-tb Models }} \\
\hline & & & & & & & & & & & \\
\hline & & \multicolumn{2}{|c|}{ 2-Story } & \multicolumn{3}{|c|}{ 3-Story } & \multicolumn{2}{|c|}{ 2-Story } & \multicolumn{3}{|c|}{ 3-Story } \\
\hline & & C1 & $\mathrm{C5}$ & $\mathrm{C1}$ & $\mathrm{C3}$ & C6 & $\mathrm{C1}$ & $\mathrm{C5}$ & $\mathrm{C1}$ & $\mathrm{C3}$ & C6 \\
\hline \multirow{4}{*}{$\theta_{\mathrm{X}, \mathrm{UPD}}$} & $\mu_{\mathrm{NLB}}$ & 0.024 & 0.014 & 0.037 & 0.025 & 0.023 & 0.027 & 0.012 & 0.041 & 0.023 & 0.021 \\
\hline & $\beta_{\mathrm{NLB}}$ & 0.07 & 0.17 & 0.11 & 0.23 & 0.19 & 0.055 & 0.19 & 0.09 & 0.22 & 0.19 \\
\hline & $\mu_{\text {macro }}$ & 0.091 & 0.053 & 0.083 & 0.046 & 0.042 & 0.091 & 0.051 & 0.077 & 0.046 & 0.041 \\
\hline & $\beta_{\text {macro }}$ & 0.09 & 0.07 & 0.072 & 0.12 & 0.15 & 0.1 & 0.09 & 0.07 & 0.12 & 0.15 \\
\hline \multirow{4}{*}{$\theta_{\mathrm{Y}, \mathrm{UPD}}$} & $\mu_{\mathrm{NLB}}$ & 0.042 & 0.013 & 0.033 & 0.017 & 0.015 & 0.042 & 0.011 & 0.022 & 0.015 & 0.014 \\
\hline & $\beta_{\mathrm{NLB}}$ & 0.39 & 0.2 & 0.16 & 0.19 & 0.17 & 0.192 & 0.183 & 0.181 & 0.2 & 0.169 \\
\hline & $\mu_{\text {macro }}$ & 0.072 & 0.15 & 0.053 & 0.036 & 0.035 & 0.064 & 0.124 & 0.047 & 0.032 & 0.032 \\
\hline & $\beta_{\text {macro }}$ & 0.08 & 0.09 & 0.16 & 0.2 & 0.17 & 0.17 & 0.17 & 0.21 & 0.20 & 0.17 \\
\hline \multirow{4}{*}{$\theta_{\mathbf{X}, \mathbf{G C}}$} & $\mu_{\mathrm{NLB}}$ & 1.19 & 0.88 & 0.81 & 0.59 & 0.69 & 1.05 & 0.96 & 0.66 & 0.60 & 0.71 \\
\hline & $\beta_{\mathrm{NLB}}$ & 0.26 & 0.31 & 0.37 & 0.25 & 0.34 & 0.33 & 0.32 & 0.32 & 0.27 & 0.37 \\
\hline & $\mu_{\text {macro }}$ & 0.82 & 0.27 & 0.66 & 0.27 & 0.30 & 0.72 & 0.27 & 0.57 & 0.24 & 0.26 \\
\hline & $\beta_{\text {macro }}$ & 0.25 & 0.16 & 0.19 & 0.27 & 0.3 & 0.2 & 0.17 & 0.18 & 0.29 & 0.36 \\
\hline \multirow{4}{*}{$\theta_{\mathbf{Y}, \mathbf{G C}}$} & $\mu_{\mathrm{NLB}}$ & 1.31 & 1.19 & 0.87 & 0.85 & 0.81 & 1.19 & 1.22 & 0.75 & 0.85 & 0.84 \\
\hline & $\beta_{\mathrm{NLB}}$ & 0.21 & 0.29 & 0.38 & 0.31 & 0.32 & 0.329 & 0.25 & 0.361 & 0.323 & 0.33 \\
\hline & $\mu_{\text {macro }}$ & 0.89 & 0.78 & 0.49 & 0.32 & 0.29 & 0.72 & 0.41 & 0.57 & 0.30 & 0.23 \\
\hline & $\beta_{\text {macro }}$ & 0.8 & 0.28 & 0.31 & 0.25 & 0.21 & 0.34 & 0.24 & 0.36 & 0.29 & 0.28 \\
\hline
\end{tabular}


The results of Table 8 and Figure 12 highlight that:

- when considering the L-tb models, the median values of the EDP thresholds are lower than the corresponding deterministic models (Table 3);

- the dispersion is limited in case of the UPD limit state (with values between 0.07 and 0.2 , except for few cases regarding the $\mathrm{C} 1$ configuration), while it is more significant for the GC limit state (with values between 0.16 and 0.38 ), as also clearly evident in Figure $12 \mathrm{a}$; this can be explained by considering that for the GC limit state an important role is played by the significant uncertainty associated with the ultimate drift capacity of masonry piers (ruled by $\Delta \theta$ variables), which strongly affects the strength deterioration of the pushover curve, hence influencing the identification of the GC threshold;

- $\quad$ relevant differences are not detected between the L-tb and the S-tb models, with both constitutive laws; this is evident also from Figure $12 \mathrm{~b}$.

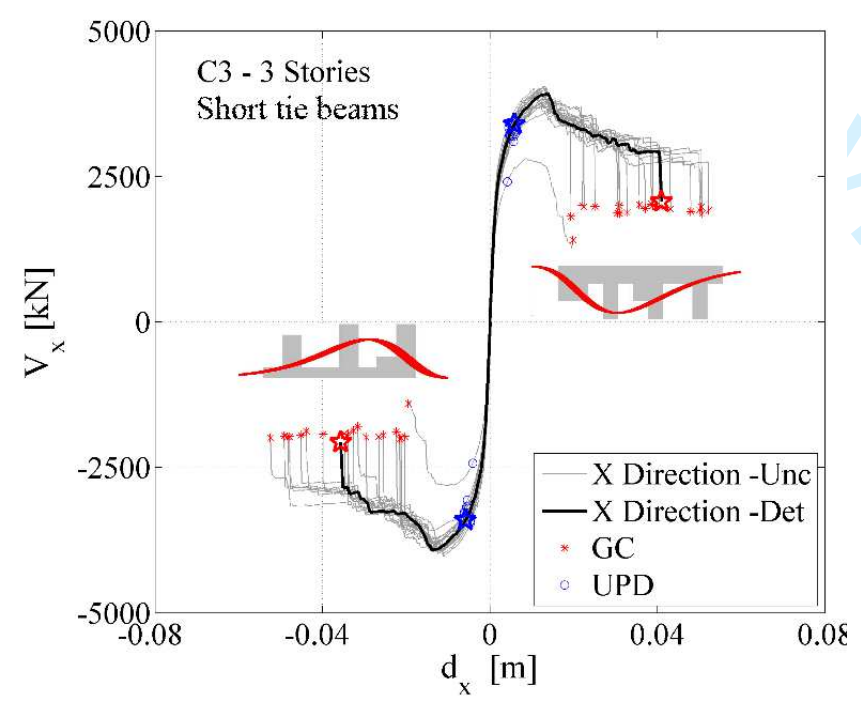

a)

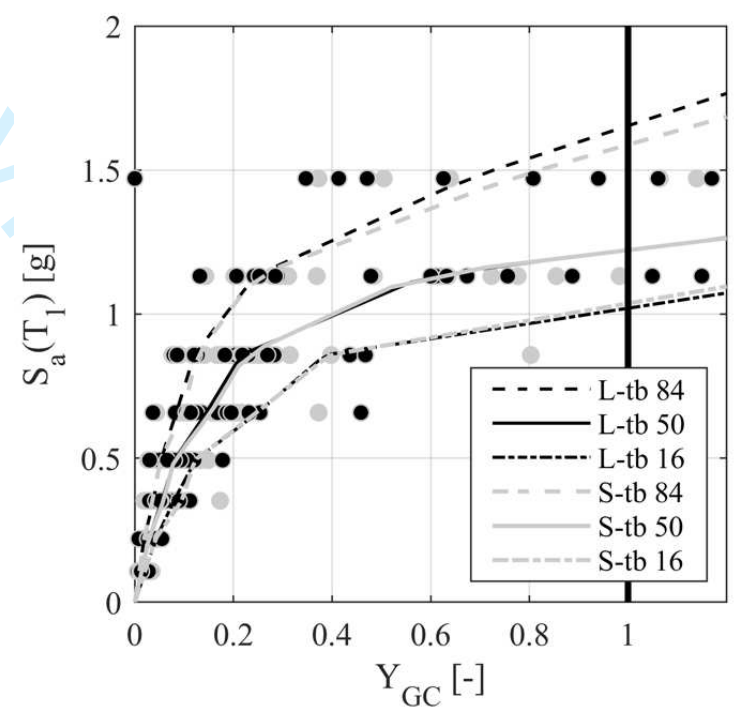

b)

Figure 12: a) Effect of the aleatory uncertainties in the definition of the EDP threshold; b) effect of the epistemic modelling uncertainties related to the effective length of the r.c. tie beams. Results refer to the adoption of the macroelement model.

The comparisons of NLDA results shown in Figure 13 highlight, for both the considered limit states, the influence of:

- $\quad$ the design method and the different possible modelling choices (Figure 13a); 
- the epistemic uncertainty associated with the constitutive model and, for each model, the effect of the structural modeling uncertainty related to the effective length of the r.c. tie beams (Figure 13b);

- the uncertainty on the aleatory variables (Figure 13c).

Figure 13a confirms the different level of conservativeness guaranteed by the design carried out applying the SB rules (adopted for building C6) or the NLSA (building C1 and C3, Table 6). In particular, C1 configuration derives from the design of an analyst who adopted S-tb and perfect connection among walls, while C3 configuration from the design of an analyst who adopted L-tb and limited connection among walls.

From Figure $13 \mathrm{~b}$ it is possible to observe that the macroelement model tends to produce higher estimates for the value of $I M_{L S, 50}$ at both limit states; in particular, for the UPD, this is due to the difference in the EDP thresholds. In both constitutive models, the role of the structural modeling uncertainty associated with the effective length of the r.c. tie beams is not so significant.

Furthermore, Figure 13c shows that the effect of uncertainty in material parameters is not very significant, although the case including this uncertainty tends to be slightly more vulnerable than the deterministic case; this result was obtained with both constitutive models.

This can be also illustrated in a more complete and systematic way through Table 9, which reports the values of $I M_{L S, 50}$ referring to the $\mathrm{C} 1$ configuration (2- and 3-story) for the two constitutive laws and for the two considered definitions of the r.c. tie beams (L-tb and S-tb). Results show that the effect of the epistemic uncertainty associated with the constitutive model is even higher than that associated with the aleatory variables. It is worth recalling that, as illustrated in detail in section 2.3 , the two models were cross-calibrated with reference to the same experimental evidences, to describe the hysteretic response and the backbone curve in a consistent way. This cross-calibration process leads to a dispersion in the results which is lower than what expected in the case of a real blind assessment provided by two different analysts.

Further considerations are possible through the dispersions that have been computed for the two limit states (LS) from the results of each stripe and from the IM- $Y_{L S}$ curves:

- dispersion of the $\mathrm{IM}_{L S}$, by considering the values corresponding to the attainment of the limit state $\left(Y_{L S}=1\right)$ from the curves associated to the $16^{\text {th }}$ and the $84^{\text {th }}$ percentiles:

$\beta_{I M, L S}=\frac{1}{2}\left[\ln \left(I M_{L S, 84}\right)-\ln \left(I M_{L S, 16}\right)\right]$ 


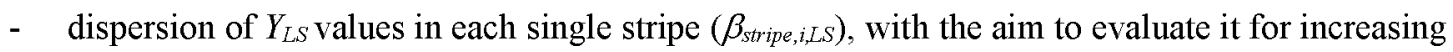
levels of the seismic action:

$$
\beta_{\text {stripe }, i, L S}=\frac{1}{2}\left[\ln \left(Y_{L S, S=i, 84}\right)-\ln \left(Y_{L S, S=i, 16}\right)\right]
$$

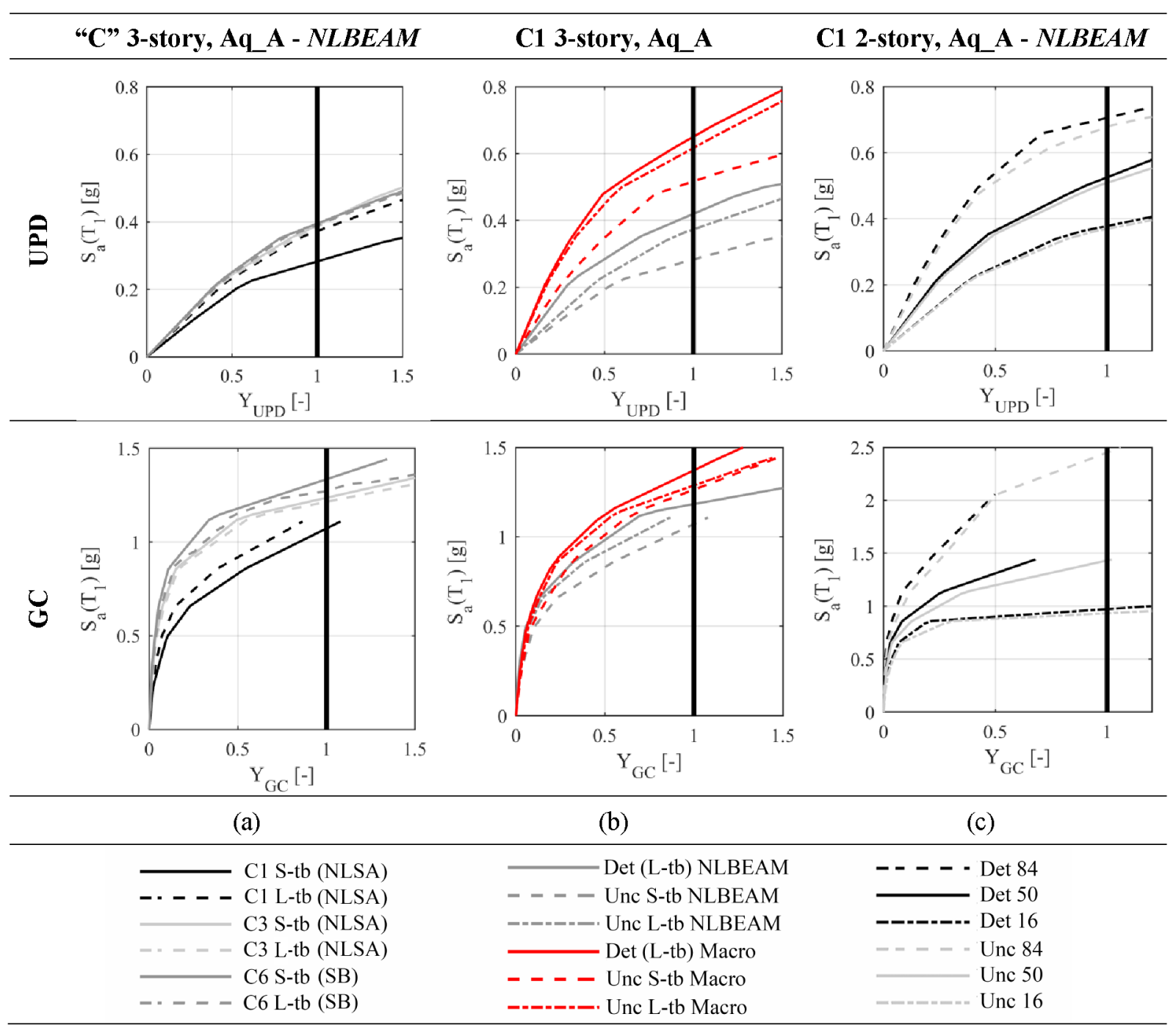

Figure 13: Curves highlighting the role played by: (a) the design method and the different possible modelling choices; (b) the epistemic uncertainties due to the constitutive models and to the different possible modelling choices; c) the effect of aleatory uncertainty in material parameters. 
Table 9. Values of IMLS,50 - in terms of spectral acceleration at $T_{l}=0.15 \mathrm{~s}$-for the two alternative models (S-tb and Ltb) and for the two considered constitutive models, in the case of $\mathrm{C} 1$ configuration.

\begin{tabular}{|c|c|c|c|c|c|c|c|}
\hline & & \multicolumn{3}{|c|}{ NLBEAM } & \multicolumn{3}{|c|}{ Macroelement } \\
\hline & & Det & Unc & Unc & Det & Unc & Unc \\
\hline & L-tb/S-tb & L-tb & L-tb & S-tb & L-tb & L-tb & S-tb \\
\hline \multirow[t]{3}{*}{ 2-story } & $\mathbf{I M}_{U P D, 50}$ & 0.54 & 0.52 & 0.51 & 1.12 & 0.98 & 0.84 \\
\hline & $\mathbf{I M}_{\mathbf{G C}, \mathbf{5 0}}$ & 1.44 & 1.44 & 1.11 & 1.64 & 1.83 & 1.35 \\
\hline & $\mathbf{I M}_{\mathrm{GC}, 50} / \mathbf{I} \mathbf{M}_{\mathrm{UPD}, 50}$ & 2.98 & 2.77 & 2.17 & 1.46 & 1.87 & 2.11 \\
\hline \multirow[t]{3}{*}{ 3-story } & IM $_{U P D, 50}$ & 0.43 & 0.38 & 0.29 & 0.65 & 0.62 & 0.53 \\
\hline & $\mathrm{IM}_{\mathrm{GC}, \mathbf{5 0}}$ & 1.22 & 1.17 & 1.07 & 1.38 & 1.29 & 1.27 \\
\hline & $\mathbf{I M}_{\mathbf{G C}, 50} / \mathbf{I} \mathbf{M}_{\mathrm{UPD}, 50}$ & 2.84 & 3.08 & 3.69 & 2.12 & 2.08 & 2.39 \\
\hline
\end{tabular}

The calculation of the dispersion in the values of limit state variable was performed both on the curves accounting only for the record to record variability $\left(\beta_{\text {rec }}\right)$ and on the curves that also include the effect of the element parameters variability $\left(\beta_{\text {elem }}\right.$ - materials and drift limits), so obtaining the total uncertainty $\left(\beta_{t o t}\right)$. By assuming the two sources of uncertainty as statistically independent, it is possible to obtain an approximate estimate of the contribution of the element variability, as $\beta_{\text {elem }}=\sqrt{\beta_{\text {tot }}^{2}-\beta_{\text {rec }}^{2}}$. Considering the values reported in Table 10, it is possible to observe that the effect of the record-to-record variability on the dispersion is similar for the two constitutive models, while the effects of the uncertainties on material parameters and element drift limits are more significant for the NLBEAM-model (especially for the GC limit state).

This result is confirmed also by what illustrated in Figure 14, showing that the value of $\beta_{\text {stripe,i,LS }}$ is almost constant until the $3^{\text {th }}-4^{\text {th }}$ stripes ( $T_{R}$ equal to 100 and 250 years, respectively), while it is significantly increasing when considering the next stripes. Regarding this aspect, it has to be observed that the attainment of the UPD occurs in correspondence of these stripes, while the GC limit state occurs between the $5^{\text {th }}$ and the $6^{\text {th }}$ stripes ( $T_{R}$ equal to 500 and 1000 years), for the $N L B E A M$-model, and between the $6^{\text {th }}$ and the $7^{\text {th }}\left(T_{R}\right.$ equal to 1000 and 2500 years), for the macroelement model.

Table 10. Values of the dispersion in $\mathrm{IM}_{\mathrm{LS}}$ obtained for the two considered limit states, considering only record-torecord variability $\left(\beta_{\text {rec }}\right)$, only element variability $\left(\beta_{\text {elem }}\right)$ or both of them $\left(\beta_{t o t}\right)$.

\begin{tabular}{|c|c|c|c|c|c|c|c|c|c|c|c|c|}
\hline \multirow[b]{3}{*}{$\mathrm{C1}$} & \multicolumn{6}{|c|}{ NLBEAM } & \multicolumn{6}{|c|}{ Macroelement } \\
\hline & \multicolumn{3}{|c|}{ GC } & \multicolumn{3}{|c|}{ UPD } & \multicolumn{3}{|c|}{ GC } & \multicolumn{3}{|c|}{ UPD } \\
\hline & $\beta_{\text {rec }}$ & $\beta_{t o t}$ & $\beta_{\text {elem }}$ & $\beta_{\text {rec }}$ & $\beta_{t o t}$ & $\beta_{\text {elem }}$ & $\beta_{\text {rec }}$ & $\beta_{t o t}$ & $\beta_{\text {elem }}$ & $\beta_{\text {rec }}$ & $\beta_{t o t}$ & $\beta_{\text {elem }}$ \\
\hline 2-Story & 0.37 & 0.48 & 0.30 & 0.31 & 0.30 & - & 0.32 & 0.38 & 0.22 & 0.23 & 0.31 & 0.20 \\
\hline 3-Story & 0.45 & 0.51 & 0.24 & 0.18 & 0.24 & 0.16 & 0.38 & 0.40 & 0.10 & 0.28 & 0.30 & 0.11 \\
\hline
\end{tabular}



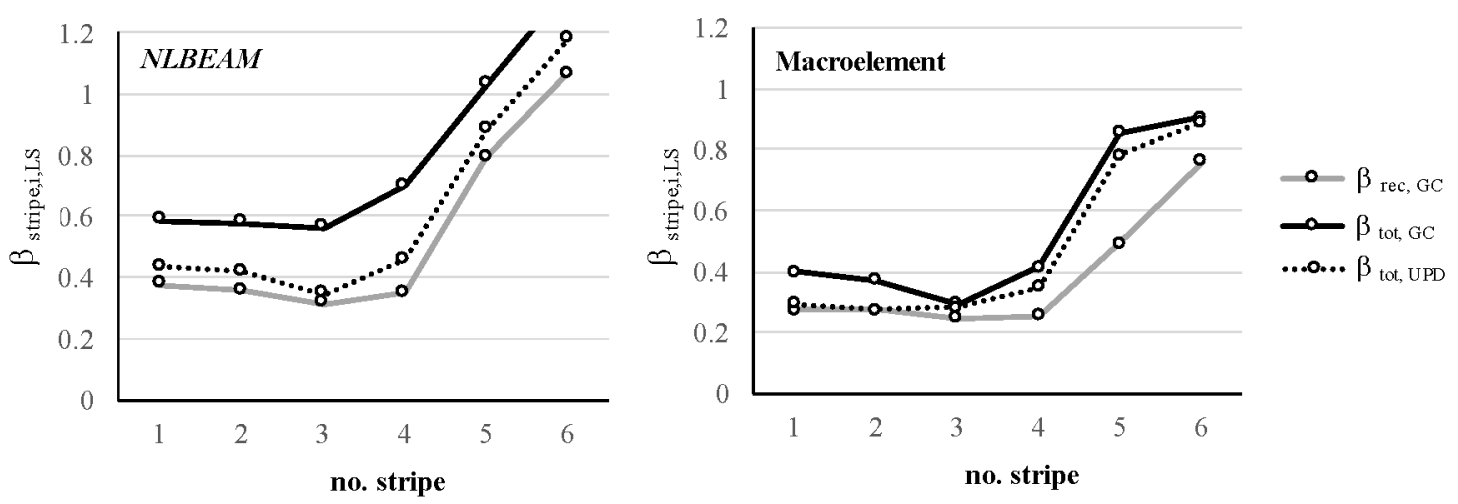

Figure 14: Values of the dispersion in the $Y_{L S}$ values for each stripe $\left(\beta_{\text {stripe, }, I S}\right)$.

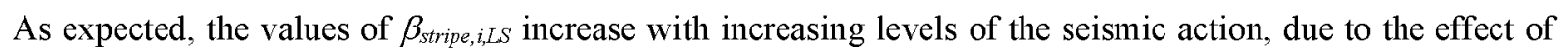
the structural nonlinearity and to the significantly scattered values of the drift capacity at the collapse. The higher dispersion observed in the case of the NLBEAM-model can be explained by considering that, in this case, the whole softening phase, and not only the value of the ultimate drift, is influenced by the relevant dispersion associated to the element parameters (in particular to the drift values corresponding to the attainment of DL3 and DL5).

\section{Conclusions}

The seismic assessment of the buildings designed as discussed in Manzini et al. (2018), carried out by nonlinear dynamic analyses, confirmed that the safety level guaranteed by the design with different methods considered by NTC08 is not uniform, even at the same site. Unreinforced masonry buildings designed by means of nonlinear static analysis turned out to be characterized by values of the intensity measure associated to the collapse condition lower than the one of buildings resulting from other design methods, in particular the linear ones. Indeed, the linear static method produces structural configurations excessively overdesigned, being walls thicker than those required by the simple building rules, which represent the simplest design approach proposed in NTC08 for URM structures. The critical issues related to linear design methods are demonstrated by the impossibility of designing a masonry building in the high seismicity zones.

The accurate seismic assessment of the building behavior was based on nonlinear models calibrated against experimental results, both in terms of appropriate strength criteria and drift limits. In particular, drift values suggested in NTC08 appear to be not conservative, at least for some modern masonry typologies, with respect 
to the experimental evidence. Indeed, the updated version of the Italian building code (NTC18 2018) proposes drift limits identified from the distribution of the available experimental results for the near collapse limit state. Analyses addressed to evaluate the role of epistemic and aleatory uncertainties in modelling confirmed that, in general, the effect of the record-to-record variability is dominant, even at the global collapse limit state. The two different constitutive models adopted provided consistent results, even if the sensitivity to structural modelling turned out to be even higher than that related to masonry material properties.

The achieved results are limited to the case of residential buildings and they refer only to masonry buildings made of vertically perforated clay units, that constitute the commonly adopted typology for load-bearing masonry in Italy. However, similar conclusions are expected for other masonry types, because buildings were designed to barely comply with code requirements, even if different drift values should be considered for the assessment of different masonry typologies (Manzini et al. 2018).

The evaluation of the seismic risk implicit in the Italian Code for different building typologies is presented in another paper of this Special Issue (Iervolino et al. 2018). Anyhow, the results obtained in this work allow to state that several aspects contribute to make NLSA in NTC08 less conservative than it should be. First of all, it adopts drift limits higher than those resulting from experiments (indeed they have been updated in NTC18), and, secondly, the procedure for the evaluation of displacement demand should be corrected to account for the specific response of short-period masonry structures (Guerrini et al. 2017, Marino et al. 2018). Regarding LSA methods, proper corrective factor and procedures (e.g. redistribution of shear forces among masonry piers) should be implemented to ease its use.

Finally, even if the assessment was made by advanced models and nonlinear dynamic analyses, the resulting vulnerability of modern URM buildings seems to be overestimated with respect to their actual behavior. Indeed, several literature reports summarizing the findings of post-earthquake reconnaissance missions (e.g. Saatcioglu and Bruneau 1993, Sucuoglu and Erberik 1997, Penna et al. 2014b, Sorrentino et al. 2018, Rosin et al. 2018) show the good performance of modern URM buildings, whose design could be also driven by other performance requirements (e.g. energy efficiency, thermal insulation, etc.). 


\section{Acknowledgements}

The study presented in this article was developed within the activities of the DPC-ReLUIS-EUCENTRE 20142018 research program, funded by Presidenza del Consiglio dei Ministri - Dipartimento della Protezione Civile; however, opinions and conclusions do not necessarily reflect those of the funding entity.

\section{References}

Bartoli G., Betti M., Biagini P., Borghini A., Ciavattone A., Girardi M., Lancioni G., Marra A.M., Ortolani B., Pintucchi B., Luca L. [2017] Epistemic uncertainties in structural modeling: a blind benchmark for seismic assessment of slender masonry towers, Journal of Performance of Constructed Facilities, 31(5),1-18.

Beyer K., Dazio A. [2012] Quasi-Static Monotonic and Cyclic Tests on Composite Spandrels, Earthquake Spectra, 28, 3, 885-906, Earthquake Engineering Research Institute.

Beyer K., Mangalathu S. [2014] Numerical study on the peak strength of masonry spandrels with arches, Journal of Earthquake Engineering. 18(2), 169-186.

Bosiljkov V., D’Ayala D., Novelli V. [2015] Evaluation of uncertainties in determining the seismic vulnerability of historic masonry buildings in Slovenia: use of macro-element and structural element modelling, Bull Earth Eng, 13 (1), 311-329.

Bracchi S., Rota M., Penna A., Magenes G. [2015] Consideration of modelling uncertainties in the seismic assessment of masonry buildings by equivalent-frame approach, Bull Earth Eng, 13 (11), 3423-3448.

Bracchi S., Galasco A., Penna A., Magenes G. [2018] An improved macroelement model for the nonlinear analysis of masonry buildings, in Proc. of the 10th Australasian Masonry Conference, 11-14 February 2018, Sydney, Australia.

CNR-DT 212/2013 [2014] Guide for the Probabilistic Assessment of the Seismic Safety of Existing Buildings, National research council of Italy.

Cattari S., Lagomarsino S. [2013] Masonry structures, 151-200. In: Sullivan T, Calvi GM (eds) Developments in the field of displacement based seismic assessment. IUSS Press and EUCENTRE, Pavia, Italy, p 524, ISBN:978-88-6198-090-7.

Cattari S., Chioccariello A., Degée H., Doneaux C., Lagomarsino S., Mordant C. [2014] Seismic assessment of masonry buildings from shaking table tests and nonlinear dynamic simulations by the Proper Orthogonal 
Decomposition (POD), in Proc. of the Second European Conference on Earthquake Engineering and Seismology (ECEES), Istanbul, 25-29 August.

Cattari S., Lagomarsino S., Karatzetzou A., Pitilakis D. [2015] Vulnerability assessment of Hassan Bey’s Mansion in Rhodes, Bulletin of Earthquake Engineering, Springer Netherlands, 13(1), 347-368.

EN1996-1-1 [2004]. Eurocode 6: design of masonry structures, Part 1: general rules for reinforced and unreinforced masonry structures, CEN, Brussels.

EN1998-3 [2005] Eurocode 8: design of structures for earthquake resistance - Part 3: Assessment and retrofitting of buildings. CEN, Bruxelles.

Franchin P., Ragni L., Rota M., Zona A. [2018] Modelling uncertainties of Italian code-conforming structures for the purpose of seismic response analysis, Journal of Earthquake Engineering - in review.

Guerrini, G., Graziotti, F., Penna, A., and Magenes, G. [2017] "Improved evaluation of inelastic displacement demands for short-period masonry structures," Earthquake Engineering and Structural Dynamics 46(9): 1411-1430.

Iervolino I. [2017] Assessing uncertainty in estimation of seismic response for PBEE, Earthquake Engineering \& Structural Dynamics, 46, 1711-1723.

Iervolino I., Spillatura A., Bazzurro P. [2018] Seismic structural reliability of code-conforming Italian buildings, Journal of Earthquake Engineering - in review.

Jalayer F. and Cornell C.A. [2002] Alternative Nonlinear Demand Estimation Methods for Probability-Based Seismic Assessments, Earthquake Engineering \& Structural Dynamics, 00, 1-6.

Jalayer F. [2003] Direct probabilistic seismic analysis: Implementing non-linear dynamic assessments, Ph.D. Dissertation, Stanford University.

Kappos A.J and Papanikolaou V.K [2016] Nonlinear dynamic analysis of masonry buildings and definition of seismic damage states, The Open Construction and Building Technology Journal, 10 (suppl 2, M2), 192209.

Lagomarsino S., Penna A., Galasco A., Cattari S. [2013] TREMURI program: an equivalent frame model for the nonlinear seismic analysis of masonry buildings, Engineering Structures, 56,1787- 1799.

Lagomarsino S. and Cattari S. [2015] Seismic performance of historical masonry structures through pushover and nonlinear dynamic analyses, 265-292, in Perspectives on European Earthquake Engineering and Seismology, vol. 2. A. Ansal Ed., Instanbul, Turkey. 
Lin T., Haselton C.B. and Baker J.W. [2013] Conditional spectrum-based ground motion selection. Part I: Hazard consistency for risk-based assessments, Earthquake Engineering \& Structural Dynamics, 42(12), 1847-1865.

Magenes G., Morandi P., Penna A. [2008] Experimental in-plane cyclic response of masonry walls with clay units, in Proc. of the 14th WCEE, Beijing, China, Paper No. 95, 8 pages.

Mann W. and Müller H. [1980] Failure of shear-stressed masonry - an enlarged theory, tests and application to shear-walls. In Proc. int. symposium on load-bearing brickwork, London, UK, 1-13.

Manzini C.F., Magenes G., Penna A., da Porto F., Camilletti D., Cattari S., Lagomarsino S. [2018] Masonry Italian code-conforming buildings: Part 1: case studies and design methods, Journal of Earthquake Engineering - in review.

Marino S., Cattari S., Lagomarsino S. [2018] Use of non-linear static procedures for irregular URM buildings in literature and codes, in Proc. of the 16th European Conference on Earthquake Engineering, 18-21 June, 2018, Thessaloniki, Greece.

Marino S., Cattari S., Lagomarsino S., Ingham J., Dizhur D. [2016] Modelling of two damaged unreinforced masonry buildings following the Canterbury earthquakes, in Proc. of Reducing risk raising resilience 2016 NZSEE Conference, Christchurch, New Zealand, 1-3 April, 2016, 10 pages.

Morandi P., Albanesi L., Magenes G. [2016] In-plane test campaign on different load-bearing URM typologies with thin shell and web clay units, in Proc. of $16^{\text {th }}$ International Brick and Block Masonry Conference, Padua, Italy.

Morandi, P., Albanesi, L., Graziotti, F., Li Piani, T., Penna, A., Magenes, G. [2018] “Development of a dataset on the in-plane experimental response of URM piers with bricks and blocks," Construction and Building Materials (under review).

Mouyiannou A., Rota M., Penna P., Magenes G. [2014] Identification of suitable limit states from nonlinear dynamic analyses of masonry structures. Journal of Earthquake Engineering, 18(2), 231-263.

NTC08 [2008] Decreto ministeriale 14/1/2008: Norme tecniche delle costruzioni. Ministero delle Infrastrutture e dei trasporti, S.O. No. 30 alla G.U. No. 29 del 4/2/2008, Ministero delle Infrastrutture e dei Trasporti, Rome, Italy (in Italian). 
NTC18 [2018] Decreto ministeriale 20/2/2018: Norme tecniche delle costruzioni. Ministero delle Infrastrutture e dei trasporti, S.O. No. 8 alla G.U. No. 42 del 20/2/2018, Ministero delle Infrastrutture e dei Trasporti, Rome, Italy (in Italian).

Parisi F., Augenti N. [2012] Uncertainty in Seismic Capacity of Masonry Buildings, Buildings, 2(3), 218-230.

Parisi F., Augenti N., Prota A. [2014] Implications of the spandrel type on the lateral behavior of unreinforced masonry walls, Earthquake Engineering \& Structural Dynamics, 43, 1867-1887.

Penna A., Lagomarsino S., Galasco A. [2014a] A nonlinear macroelement model for the seismic analysis of masonry buildings, Earthquake Engineering \& Structural Dynamics, 43(2), 159-179.

Penna A., Morandi P., Rota M., Manzini C., da Porto F., Magenes G. [2014b] Performance of masonry buildings during the Emilia 2012 earthquake, Bull Earthq Eng 12, 2255-2273.

Petry S., Beyer K. [2014] Influence of boundary conditions and size effect on the drift capacity of URM walls, Engineering Structures, 65, 76-88.

RINTC Workgroup [2018] Results of the 2015-2017 implicit seismic risk of code-conforming structures in Italy (RINTC) project. ReLUIS-EUCENTRE report, available at http://www.reluis.it/

Rosin, J., Butenweg, C., Cacciatore, P., Boesen, N. [2018] "Investigation of the seismic performance of modern masonry buildings during the Emilia Romagna earthquake series," Mauerwerk, 22(4):238-250.

Rota M., Penna A., Magenes G. [2014] A framework for the seismic assessment of existing masonry buildings accounting for different sources of uncertainty, Earthquake Engineering and Structural Dynamics, 43(7), 1045-1066.

Saatcioglu M., Bruneau M. [1993] Performance of structures during the 1992 Erzincan earthquake. Canadian Journal of Civil Engineering, 20:305-325.

Sorrentino L., Cattari S., aa Porto F., Magenes G., Penna A. [2018] Seismic behavior of ordinary masonry buildings during the 2016 central Italy earthquakes, Bull Earthq Eng, DOI:10.1007/s10518-018-0370-4.

Sucuoglu H., Erberik A. [1997] Performance evaluation of a three-storey unreinforced masonry building during the 1992 Erzincan earthquake. Earthquake Engineering \& Structural Dynamics 26:319-336.

Tomazevic M. [1987] Dynamic Modelling of Masonry Buildings: Storey Mechanism as a Simple Alternative, Earthquake Engineering \& Structural Dynamics, 15(6),731-749. 
Turnšek V, Sheppard P. [1980] The shear and flexural resistance of masonry walls. In Proc. int. research conference on earthquake engineering, Skopje, Macedonia; 517-573 